\title{
ADVANCING FRACTURE FRAGILITY ASSESSMENT OF PRE-NORTHRIDGE WELDED COLUMN SPLICES
}

\author{
Biao Song ${ }^{1}$, Carmine Galasso ${ }^{1}$, and Amit Kanvinde ${ }^{2}$ \\ ${ }^{1}$ Department of Civil, Environmental \& Geomatic Engineering, University College London, London, UK \\ ${ }^{2}$ Department of Civil and Environmental Engineering, University of California, Davis, CA 95616, USA
}

\begin{abstract}
SUMMARY
A refined probabilistic assessment of seismic demands and fracture capacity of Welded Column Splice (WCS) connections in welded steel moment resisting frames (WSMRFs) is presented. Seismic demand assessment is performed through cloudbased nonlinear time history analysis (NLTHA) for two case-study structures, i.e. a 4- and a 20- story WSMRFs. Results from NLTHA are assessed through a probabilistic seismic demand analysis framework to derive fracture fragility of WCS connections. To this aim, the study investigates (1) optimal ground-motion intensity measures for conditioning probabilistic seismic demand models in terms of global (i.e., maximum inter-story drift ratio) and local (i.e., peak tensile stress in the flange of WCSs) engineering demand parameters of WSMRFs; (2) the effect of ground-motion vertical components on the longitudinal flange stress of WCS connections and their resulting fracture fragility; and (3) the effect of WCS capacity uncertainties on the fracture fragility estimates of those connections. For the latter case, an advanced Finite Element Fracture Mechanics-based approach proposed by the authors is employed to capture aleatory and epistemic uncertainties affecting fracture capacities. The focus is on pre-Northridge WCS connections featuring partial joint penetration and brittle materials, making them highly vulnerable to seismic fracture. Fracture fragility results for the case-study structures are compared and discussed, highlighting the importance of the considered issues on fragility estimates, particularly in the case of high-rise structures. Findings from the study contribute shedding some light on the influence of seismic demand and capacity uncertainties on the assessment of fracture fragility of WCS connections. These findings can guide similar performancebased assessment exercises for WSMRFs to inform, for instance, the planning and design of retrofitting strategies for those vulnerable connections.
\end{abstract}

\section{KEYWORDS}

pre-Northridge welded column splice; demand and capacity uncertainties; fracture fragility; ground-motion intensity measures; vertical component

\section{INTRODUCTION AND MOTIVATIONS}

Welded steel moment resisting frames (WSMRFs) are a popular load-resisting system on the West Coast of the United States and in other seismically active regions. This is mainly due to their architectural versatility and ductility features. Over the last two decades, the design and detailing practice for WSMRFs have undergone tremendous changes. In large part, these changes are the results of extensive experimental and analytical/numerical research studies - notably the US Federal Emergency Management Agency (FEMA)-funded SAC Steel Project (e.g., Alali et al. ${ }^{[1]}$; Anderson et al. ${ }^{[2]}$; Kaufman and Fisher ${ }^{[3]}$; Maison et al. $\left.{ }^{[4]}\right)$. These studies were conducted in response to brittle fractures observed in welded beam-to-column (WBC) connections in WSMRFs during the 1994 M6.7 Northridge earthquake ${ }^{[5]}$. These various studies revealed that numerous factors were responsible for the observed fractures, including: (1) the use of low-toughness weld and base materials; (2) poor detailing and construction practices such as improper access holes, left-in-place backing bars, and runoff tabs that created notch conditions and prevented visual inspection; and (3) connection design factors such as inadequate participation of the web resulting in higher stresses in the flanges. As a result, recommendations from these studies (now codified in AISC 341-16 ${ }^{[6]}$ ) mandate improved material toughness and detailing requirements for all new welded steel connections within WSMRFs in addition to guidelines for the retrofit of vulnerable pre-Northridge connections (FEMA 354 ${ }^{[7]}$ ). In pre-Northridge frames, application of these retrofit strategies has largely been focused on WBC connections, given that: (1) fractures were observed exclusively within these connections after the Northridge earthquakes; and (2) their location, adjacent to the beam plastic hinge, is particularly critical. On the other hand, a large majority of Welded Column Splice (WCS) connections were, for the most part, not checked for fracture after the Northridge earthquake, and many have not been retrofitted. This may be attributed to the potential operational disruption and liability issues that may arise from such inspections. Nonetheless, numerous studies including those by the authors (e.g., Galasso et al. ${ }^{[8]}$ ) and practitioners (e.g., Nudel et al. ${ }^{[9]}$ ) indicate a very high likelihood of such fractures, such that WCS retrofit is a priority for numerous pre-Northridge buildings. Figure 1 illustrates the location and detail of a typical pre-Northridge WCS. These connections are common in midto high-rise WSMRFs due to transportation limitations on column height and to facilitate transitioning of column sizes through the height of a structure. 


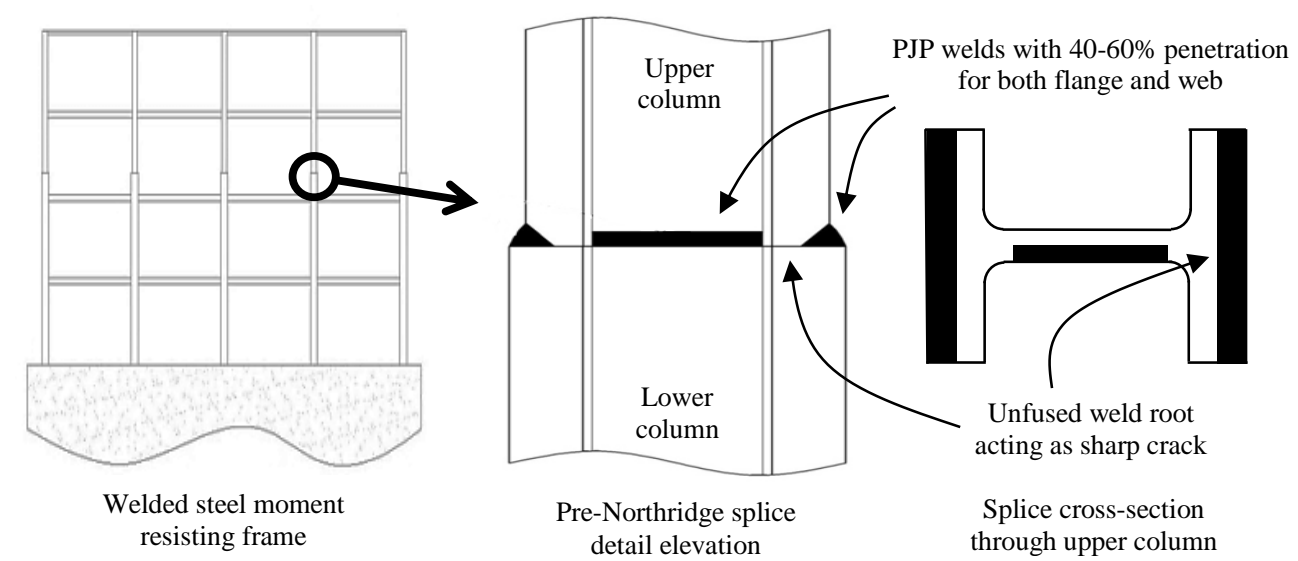

Figure 1 Example of Welded Column Splice (WCS) with Partial Joint Penetrations (PJP) in pre-Northridge welded steel moment resisting frames (WSMRFs)

Referring to Figure 1, pre-Northridge WCS connections typically feature Partial Joint Penetration (PJP) welds with low flange weld penetrations (effective weld throat) in the range of 40-60\% of the thinner connected flange thickness, producing a crack-like flaw at the root of PJP welds. This flaw is perpendicular to the longitudinal tensile stress in the flanges when the column is under axial tension or flexure during seismic events; therefore, it is detrimental from the standpoint of fracture capacity ${ }^{[10]}$. Additionally, the typical weld filler materials of pre-Northridge WCS connections are characterized by Charpy V-Notch $(\mathrm{CVN})$ energy values between $6.8-13.6$ Joules $(\mathrm{J})^{[11]}$. These $\mathrm{CVN}$ values are significantly lower than the CVN toughness value (i.e., $27 \mathrm{~J}$ at $-18{ }^{\circ} \mathrm{C}$ ) mandated by AISC $341-16^{[6]}$, resulting in significantly lower fracture capacity of such connections. This observation has also been confirmed by experimental studies on WCSs prior to Northridge earthquake (e.g., Bruneau and Mahin $^{[12]}$ ) and subsequent Finite Element Fracture Mechanics (FEFM) simulations based upon these tests ${ }^{[13]}$, as well as a recent FEFM simulations by Stillmaker et al. ${ }^{[10]}$. Based on these studies, pre-Northridge WCSs are expected to fracture at flange stresses in the range of $103-172$ $\mathrm{MPa}$, much lower than the expected flange yielding strength (i.e., $400 \mathrm{MPa}$ ) as specified by the current seismic provision (i.e., AISC 341-16 ${ }^{[6]}$ ).

Conventionally, seismic demands in WCSs are estimated to be modest under first-mode building response, since the typical location of WCSs as required by design standards (i.e., AISC $341-16^{[6]}$ ) is near the mid-story, where the bending moment is low due to double-curvature bending of columns. Significant axial forces and moment demands are nonetheless possible at these locations, as noted in recent nonlinear time history analysis (NLTHA) simulations $^{[14,15]}$. This trend is pronounced in high-rise frames, where the temporal peak of tensile stresses in the column flanges of WCSs is comparable to the yield stress of the flange. This is attributable to the participation of higher dynamic modes (which causes single-curvature bending of columns) and overturning (which results in tension of columns).

Galasso et al ${ }^{[8]}$ recently conducted a rigorous probabilistic seismic demand analysis (PSDA), fracture fragility (i.e., likelihood of fracture experienced by WCSs over a range of ground-motion hazard intensities) derivation, and fracture risk assessment of WCSs, adopting a performance-based earthquake engineering (PBEE) framework. Findings from this study indicate that high longitudinal stress demands coupled with low fracture capacities in preNorthridge WCSs result in unacceptably high fracture risk. This is especially true in pre-Northridge WSMRFs with WCSs featuring PJP welds with crack-like flaws, resulting in relatively low expected return periods of fracture, on the order of 75 years. This is clearly unacceptable, considering current acceptance criteria for building performance (ASCE 7-16 $\left.{ }^{[16]}\right)$.

The approach used in Galasso et al ${ }^{[8]}$ relied on some simplifying, practical assumptions, particularly in accounting for the uncertainties related to stress demands and fracture capacities of WCSs. Thus, while these results provide an important first-order estimate of fracture risk in existing buildings, they do not take advantage of major advancements of PBEE research, as it pertains to explicit quantification of uncertainties, both aleatory and epistemic, impacting the assessment of seismic performance (e.g., Bradley ${ }^{[17]}$ ) and, specifically, of WCS fracture fragility. For instance, the previous studies rely on the (pseudo-) spectral acceleration at the fundamental period of the structure $S_{a}\left(T_{1}\right)$ as the sole ground-motion intensity measure (IM). This is questionable for several reasons, including that it is agnostic to 
higher-mode effects, which clearly drive WCS stress demands, particularly in high-rise structure. Thus, it is important to select an IM enabling more accurate estimation of seismic demands by (1) minimizing the record-to-record variability (efficiency); (2) reducing the effect of (other) seismological parameters (sufficiency); and (3) offering hazard computability such that it may be conveniently determined through existing Ground-Motion Models (GMMs) and hazard curves or maps.

Also, all previous studies quantifying WCS seismic demands (including Galasso et al ${ }^{[8]}$ ), do not consider the effect of vertical ground shaking on stress demands in WCSs of mid- to high-rise WMRFSs. This is concerning because it is well known that the vertical component of seismic motions may contribute significantly to the seismic demands imposed on structures. Post-earthquake reconnaissance has confirmed that building damage occurring during the Kalamata, Greece (1986), the Northridge, California (1994), the Kobe, Japan (1995), and the L'Aquila, Italy (2009) earthquakes, among others, could be attributed to intense vertical shaking (e.g., Papazoglou and Elnashai ${ }^{[18]}$; Bozorgnia et al. ${ }^{[19]}$; and Di Sarno et al. ${ }^{[20]}$ ).

Finally, Galasso et al. ${ }^{[8]}$ considered a deterministic value of the fracture capacity (denoted as $\sigma_{C}$ ) for each splice of interest based on FEFM simulations, without considering uncertainty in these capacities which are often significant. Collectively, these simplifying assumptions and subjectivities have the potential to strongly affect the estimated WCS fracture fragility and risk. Accurate estimation of fracture fragility and risk is particularly critical, since: (1) given their structural function, the fracture risk of WCS has major implications for occupant safety and thus, decisions regarding retrofit; and (2) given their location, repair/retrofit of WCS is costly and enormously disruptive to building operations. Within this context, the current study aims to refine simulation-based fracture fragility assessment for WCS connections, utilizing state-of-the-art research tools, advancing some of them, and putting them into a coherent and harmonized overall approach that is practical to implement. Specifically, the objectives of this study are:

(1) To investigate and select the optimal IMs for conditioning probabilistic seismic demand models in terms of global (i.e., maximum inter-story drift ratio, MIDR) and local (i.e., peak tensile stress in the flange of WCSs, $\sigma_{D}$ ) engineering demand parameters (EDPs) of WSMRFs. Particularly, this study aims to investigate the effect of higher modes on $\sigma_{D}$ through more sophisticated IMs accounting for spectral shape over a range of periods. The resulting optimal IMs are incorporated in the fracture fragility assessment framework proposed in this study;

(2) To investigate the effect of the ground-motion vertical component on $\sigma_{D}$ and resulting fracture fragility;

(3) To incorporate the uncertainty in the fracture capacity of WCSs $\left(\sigma_{C}\right)$ into the fracture fragility assessment, through a FEFM-based approach recently developed by the authors ${ }^{[10]}$ and a detailed uncertainty characterization.

The paper begins by introducing the key factors potentially impacting the uncertainty in seismic demands to WCSs (Section 2). This is followed by the introduction of case studies, wherein two WSMRF models are investigated through NLTHA (Section 3). Section 4 focuses on the FEFM-based determination of WCS fracture capacity, as well as the uncertainty characterization of fracture capacity. Section 5 synthesizes these results, providing a critical examination of the fracture fragility, considering these various factors. The paper concludes (Section 6) by summarizing the findings of this study.

\section{SEISMIC DEMAND MODELLING}

Two key issues affecting seismic demand uncertainty (in terms of global and local EDPs, i.e., MIDR and $\sigma_{D}$ ) of WCSs are reviewed and discussed in this section. They are (1) ground-motion IM 'optimization'; and (2) inclusion of ground-motion vertical component for performance-based seismic demand assessment of WCSs.

\subsection{Selection of Optimal IMs for Predicting Global and Local EDPs}

A fundamental issue in the framework of PBEE is the choice of optimal ground-motion IMs for conditioning probabilistic seismic demand models. Ground-motion IMs are parameters synthetically describing the intensity of ground motions in terms of their effects (e.g., damage potential and loss) on structures. IMs play an important role in PBEE and in ground-motion selection procedures, because they link the seismic hazard at a given site and seismic demand analysis for a given structure, thus facilitating probability-based seismic risk assessment. The selection of a single (or a vector of) 'right' $\mathrm{IM}(\mathrm{s})$ for building-specific fragility (and vulnerability) characterization has been the subject of a very fertile body of research for at least twenty years. In fact, it is widely accepted that seismic structural performance prediction based on conventional (scalar) ground-motion parameters are subjected to a great deal of variability, which in turn requires greater computational effort to obtain seismic demand estimates with a reasonable 
level of confidence. A comprehensive overview of this previous research is not within the scope of this paper, but some key issues related to optimal IM selection are briefly reviewed here.

Generally, optimal IMs should be able to capture as many as possible ground motion properties (e.g., amplitude, frequency content) that could substantially impact both elastic and inelastic seismic demands (e.g., Freddi et al. ${ }^{[21]}$ ). In this study, only those IMs defined based on elastic spectral ordinates and associated structural dynamic characteristics (i.e., modal and elongated periods) are considered ${ }^{\mathrm{I}}$ and compared/evaluated by the following criteria: (1) efficiency; (2) sufficiency/relative sufficiency; and (3) hazard computability. The general overview of the selection criteria for optimal IMs can be found in Baker and Cornell ${ }^{[22]}$; Luco and Cornell ${ }^{[23]}$; and Padgett et al. ${ }^{[24]}$ among others.

The selection of optimal IMs for predicting global and local EDPs of WSMRFs carried out in this study is based on (1) the use of a large dataset of (unscaled) recorded earthquake ground motions; (2) numerical analyses performed on highly detailed and advanced numerical models; and (3) systematic statistical analysis of the results. These aspects are introduced in the following sub-sections.

\subsubsection{Considered IMs}

Conventional IMs, including the peak ground quantities (i.e., peak ground acceleration, PGA; peak ground velocity, PGV; and peak ground displacement, PGD) and $S_{a}\left(T_{1}\right)$, for 5\% damping, are the most commonly used IMs. In general, PGA and $S_{a}\left(T_{1}\right)$ poorly predict demand parameters of mid- to high-rise moment resisting frames, although the latter IM can sufficiently capture the elastic behavior of first-mode dominated multi degree of freedom (MDoF) systems, especially in the case of low-to-moderate fundamental periods. However, the behavior of highly nonlinear structures or structures dominated by higher-mode periods (less than $T_{1}$ - in cases where higher-mode effects are significant, e.g. high-rise structures) is not very well captured by utilizing $S_{a}\left(T_{1}\right)$ due to the lack of information on the spectral-shape (in the range of periods of interest) provided by this IM. Therefore, it is essential to implement advanced IMs accounting for the multiple periods and/or consider nonlinear demand-dependent structural parameters. Kazantzi and Vamvatsikos ${ }^{[25]}$, Eads et al. ${ }^{[26,27]}$, and Kohrangi et al. ${ }^{[28]}$ amongst others have investigated the adequacy of numerous advanced scalar IMs that take into consideration the aforementioned parameters.

Specifically, this study investigates an advanced scalar IM option, $I_{N p}$, which is based on $S_{a}\left(T_{1}\right)$ and a parameter proxy for the spectral shape $\left(N_{p}\right)$, expressed as:

$$
I_{N p}=S_{a}\left(T_{1}\right) \cdot N_{p}^{\alpha}
$$

It was first introduced by Bojórquez and Iervolino ${ }^{[29]}$, as an improvement of the geometric mean of several spectral acceleration values at different periods, $S_{a, a v g}\left(T_{i}\right)$, first proposed by Baker and Cornell ${ }^{[30]}$ :

$S_{a, a v g}\left(T_{i}\right)=\left(\prod_{i=1}^{n} S_{a}\left(T_{i}\right)\right)^{1 / n}$

In Eq. (1), $N_{p}$ is defined as:

$$
N_{p}=\frac{S_{a, \text { avg }}\left(T_{i}\right)}{S_{a}\left(T_{1}\right)}
$$

The value for the exponential parameter of $N_{p}$ in Eq. (1), $\alpha$, must be calibrated during the optimal IM selection process. Bojórquez and Iervolino ${ }^{[29]}$ provided some recommendations for the $\alpha$-value for case-study structures (e.g., WSMRFs); recently, Minas and Galasso ${ }^{[31]}$ have calibrated the $\alpha$-parameter for simplified fragility analysis of mid-

\footnotetext{
I Integral (e.g., duration-related) IMs, e.g., the Arias intensity or significant ground motion duration, are not considered here. In fact, they are usually considered related more to the cyclic energy dissipation rather than to the peak structural response. WSMRFs are less sensitive to such a cyclic energy dissipation.
} 
rise reinforced concrete (RC) case-study frames, representative of different vulnerability classes (Pre-, Low- and Special-code design), providing a critical discussion on the possible outcomes of the calibration for the $\alpha$-parameter.

In this study, ten different values of $\alpha$, ranging from 0.1 to 1 with 0.1 increments, are tested to determine the optimal $\alpha$-value. Also, it is worth noting that the $S_{a}\left(T_{1}\right)$ and the $S_{a, a v g}\left(T_{i}\right)$ correspond to specific cases of $I_{N p}$ when $\alpha$ is equal to zero and one, respectively.

It is understood that, for some structures, the contribution to response from higher modes can be significant. Very often, though, the response is mainly dominated by the first few modes. To account for various structural dynamic features of the considered case-study structures, the second, third and fourth modal periods (denoted as $T_{2}, T_{3}$ and $T_{4}$ ) and an 'elongated' period (conventionally assumed equal to $1.5 T_{1}$ ) are also specified, together with the structure fundamental period $\left(T_{1}\right)$. This results in different 'periods groups' $\left(T_{i}\right)_{j}$ considered in the definition of $I_{N p}$, as follows:

(1) Two periods, defined as $\left(T_{i}\right)_{1}=\left[T_{1}, 1.5 T_{1}\right]$;

(2) Three periods, defined as $\left(T_{i}\right)_{2}=\left[T_{2}, T_{1}, 1.5 T_{1}\right]$;

(3) Four periods, defined as $\left(T_{i}\right)_{3}=\left[T_{3}, T_{2}, T_{1}, 1.5 T_{1}\right]$;

(4) Five periods, defined as $\left(T_{i}\right)_{4}=\left[T_{4}, T_{3}, T_{2}, T_{1}, 1.5 T_{1}\right]$.

In total, 41 IMs (i.e., $S_{a}\left(T_{1}\right)$ plus a combination of four periods groups and 10 considered values of the $\alpha$ parameter) are considered and investigated in this study.

\subsubsection{IM efficiency}

Efficiency is the most commonly used quantitative criterion for the selection of optimal IMs; this criterion quantifies the variability of demand estimates for different values of a given IM (e.g., Padgett et al. ${ }^{[24]}$ ). Specifically, more efficient IMs result in a reduced dispersion of the median EDP estimates conditional to a given IM. Thus, less analysis runs are needed to narrow down the confidence intervals for those estimates. The most efficient IM, best predicting a given EDP, is the one providing the largest value of the coefficient of determination, $R^{2}$, among those considered or, equivalently, as in this study, the one with the smallest value of the standard deviation, $s$, of (the natural logarithm of) the considered EDP given the IM.

\subsubsection{IM sufficiency and relative sufficiency}

Different approaches exist for the assessment of IM sufficiency. In particular, Padgett et al. ${ }^{[24]}$, among others, define sufficiency as a criterion characterizing the level of IM statistical independence conditional to specific earthquake characteristics, such as source-to-site distance $(D)$ and magnitude $(M)$. According to this approach, sufficiency is quantified based on the residual dependence on $D$ and $M$ obtained through regression analysis. Therefore, the demand estimates obtained from sufficient IMs are not correlated (or poorly correlated) with the ground-motion parameters $D$ and $M$. However, hypothesis testing results on that correlation (and the corresponding $p$-value analysis) mainly provides a binary evaluation of the IM (i.e., sufficient or insufficient) without offering any indication concerning the level of insufficiency, when this is detected. More in general, hypothesis-testing results do not explicitly quantify the relative performance of different, sufficient or insufficient, candidate IMs.

As an alternative measure of ground-motion sufficiency, relative sufficiency has been recently proposed by Jalayer et al. ${ }^{[32]}$. In particular, this measure investigates the relative sufficiency of a second $\mathrm{IM}, \mathrm{IM}_{2}$, with respect to a first one, $\mathrm{IM}_{1}$. This measure is derived based on information theory concepts and quantifies the suitability of one intensity measure relative to another. Specifically, the relative sufficiency measure, denoted herein as $I\left(E D P\left|\mathrm{IM}_{2}\right| \mathrm{IM}_{1}\right)$, is equal to the average difference between the information gained (measured in terms of Shannon entropy or simply entropy) about the performance variable EDP given $\mathrm{IM}_{1}$ and $\mathrm{IM}_{2}$, and that gained given $\mathrm{IM}_{1}$ only. If $I\left(E D P\left|\mathrm{IM}_{2}\right| \mathrm{IM}_{1}\right)$ is positive, it means that on average $\mathrm{IM}_{2}$ provides more information about EDP than $\mathrm{IM}_{1}$; therefore, $I_{2}$ is more sufficient than $I_{1}$. Similarly, if $I\left(E D P\left|I_{2}\right| I_{1}\right)$ is negative, $I_{2}$ is less sufficient than $\mathrm{IM}_{1}$. This measure is numerically expressed as: 
$I\left(\mathrm{EDP}\left|\mathrm{IM}_{2}\right| \mathrm{IM}_{1}\right) \cong \frac{1}{N} \sum_{i=1}^{N} \log _{2} \frac{p\left[\mathrm{EDP}=e d p_{i} \mid \mathrm{IM}_{2}\right]}{p\left[\mathrm{EDP}=e d p_{i} \mid \mathrm{IM}_{1}\right]}$

In Eq. (4), $N$ is the total number of selected ground motions (refer to Section 3.2 later), $e d p_{i}$ is the EDP value corresponding to the $i$-th ground motion obtained through NLTHA, and $P\left[\mathrm{EDP}=e d p_{i} \mid \mathrm{IM}\right]$ is the probability density function (PDF) of $e d p_{i}$ given specific IM. More details on the derivation of Eq. (4) are provided in Jalayer et al. ${ }^{[32]}$. The relative sufficiency measure is estimated for each performed cloud analysis (described in Section 3.3 subsequently) and is measured in units of bits of information. According to Jalayer et al. ${ }^{[32]}$, the relative sufficiency measure provides a preliminary ranking of candidate $\mathrm{IM}_{2}$ with respect to the reference $\mathrm{IM}_{1}$. The approximation of Eq. (4) can be used for a fast screening of various candidate IMs.

\subsubsection{Hazard computability}

Hazard computability describes the process to obtain the earthquake hazard at a given site in terms of a considered IM. Numerous hazard maps and GMMs (or attenuation laws) exist for the most commonly used IMs, i.e., PGA and spectral ordinates at given periods (representing sometimes a restricted range of possible discrete periods), making these IMs more favorable from the hazard-computability perspective. Other IMs (such as spectral ordinates at the actual fundamental and/or elongated periods and advanced IMs) may require interpolation or supplementary information, making the computation of the hazard a more time-consuming process; however, they are still hazard computable, as shown in Minas and Galasso ${ }^{[31]}$, among others.

\subsection{The Effects of Earthquake Ground-Motion Vertical Components}

This sub-section summarizes some relevant previous studies assessing the effects of the ground-motion vertical component on seismic structural response of steel moment resisting frames (SMRFs). Given the primary interest in WCS fracture, a specific type of EDP (i.e., axial force in the columns) under vertical ground shaking has been considered in all the selected studies.

Field evidence reported by Papazoglou and Elnashai ${ }^{[18]}$ of steel building damage from three earthquakes, including Kalamata, Greece (1986), Northridge, California (1994) and Kobe, Japan (1995), reveals the possibility of column brittle tensile failure due to high axial force, attributable to strong vertical ground-motion components.

The rest of the considered studies deals with simulation-based (i.e., numerical) investigations on the effect of the ground-motion vertical component. For instance, Papaleontiou and Roesset ${ }^{[33]}$ have studied four 3-bay SMRFs with 4-, 10-, 16- and 20-story, respectively. These considered case-study frames were designed to represent a broad range of vertical to horizontal periods ratios. Linear time history analysis (LTHA) of these four frames was performed using the 1989 Loma Prieta record from the Capitola station (PGA values of vertical and horizontal motions are $0.52 \mathrm{~g}$ and $0.47 \mathrm{~g}$, respectively); separate horizontal and vertical components of the seismic records, and their simultaneous action were considered without the inclusion of gravity loads. In these particular cases, the observed axial forces induced by the vertical shaking in both the interior and exterior columns, owing a comparable magnitude to horizontal motion, were larger than the corresponding axial forces caused by the horizontal ground shaking only. Similar results and conclusions were drawn by other researchers. For instance, Salazar and Haldar ${ }^{[34]}$ developed a time-domain nonlinear finite element computer program to evaluate the seismic responses of SMRFs by applying the horizontal and vertical components of 13 earthquake ground motion (one record from EI Centro earthquake of 1940 and 2 ground motions recorded during the 1994 Northridge earthquake) simultaneously; similarly, Macrae et al. ${ }^{[35]}$ carried out inelastic NLTHAs of nine 2D SMRFs using a suite of ground-motion records with different characteristics to estimate the effect of vertical component of ground shaking. More recently, a low-rise code-compliant SMRF was designed by Di Sarno ${ }^{[36]}$ and was subjected to combined horizontal and vertical earthquake loading of seven records from the 2011 Christchurch (New Zealand) earthquakes, characterized by a large ratio between vertical and horizontal PGAs. Both LTHA and NLTHA were performed and the previous observations on the structural response (specified as axial forces) in steel columns were confirmed by the author.

In general, all these researches observed greater axial stresses in columns caused by strong vertical shaking and highlighted that the increase of axial stress could exceed by far the compression force due to gravity load. 


\section{CASE-STUDY STRUCTURES, NONLINEAR MODELLING, AND RECORD SELECTION}

The first step of this study consists in performing NLTHA of case-study structures, then estimating the probability distributions of the considered EDPs (i.e., MIDR and $\sigma_{D}$ ) conditional on each considered IM. Such conditional probability distributions can be obtained through various types of NLTHA procedures ${ }^{[37]}$. Particularly, the one employed here is cloud analysis ${ }^{[38]}$. For illustrative proposes, two case-study WSMRF computational models (both featuring WCSs) are developed and assessed through different sets of unscaled (real) ground motions with the aim of addressing the issues described in Section 2.

\subsection{Case-Study Frame Models}

In this study, two generic frames (i.e., 4-story and 20-story), schematically illustrated in Figure 2, are considered. Both frames are similar to the frames used by Shen et al. ${ }^{[14]}$, Shaw et al. ${ }^{[15]}$, and afterward by Galasso et al. ${ }^{[8]}$, for seismic demand characterization of WCSs. These structures are adapted from those examined in the SAC steel project ${ }^{[5]}$ in terms of the geometry (i.e., same floor plans and elevations) and design, with the difference that the 3-story SAC model building is replaced by a 4-story building to accommodate the WCS (which is uncommon for buildings with less than three stories). The considered frames are assumed to be designed for seismicity (and typical gravity loading for office occupancy) consistent with the Los Angeles area, California, assuming firm soil conditions (i.e., NEHRP National Earthquake Hazards Reduction Program - Site Class D).

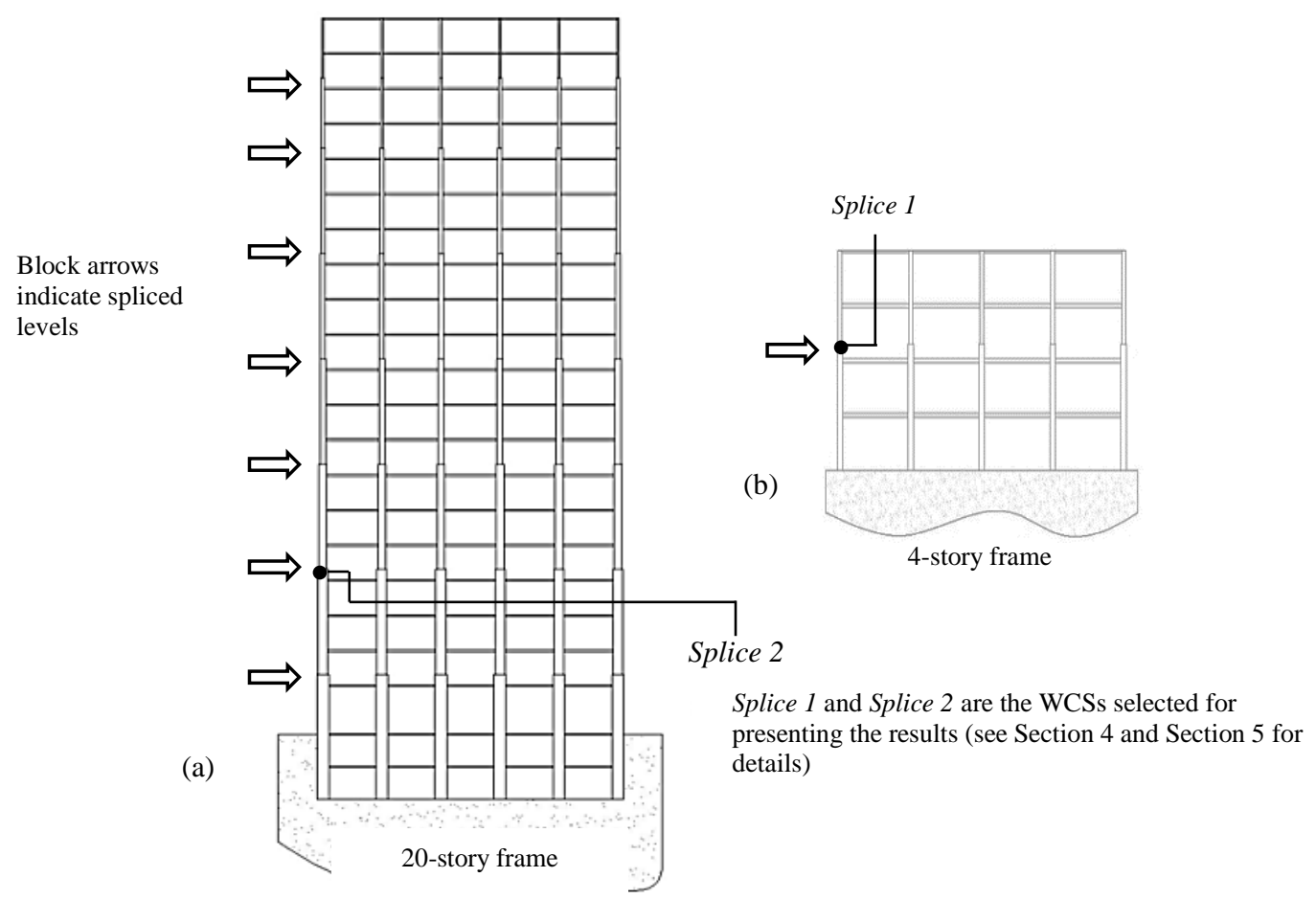

Figure 2 Schematic illustration of (a) 20-story; and (b) 4-story case-study building models (adapted from Galasso et al. ${ }^{[8]}$ )

Based on these assumptions, the case-study frames are designed as per ASCE 7-05 ${ }^{[39]}$ and AISC $341-10^{[40]}$. The first four horizontal modal periods (denoted as $T_{1}, T_{2}, T_{3}$ and $T_{4}$ ) and the fundamental vertical period (symbolized as $T_{V}$ ) calculated from elastic modal analysis for the 4-story and 20-story frames are listed in Table 1. Greater details related to the building design (e.g., design assumptions, loading conditions and frame member size specifications) can be found in Shaw ${ }^{[41]}$ and Shaw et al. ${ }^{[15]}$.

It is important to acknowledge here that, despite being designed as per codes and standards developed after the Northridge earthquake, the stress demands in the splices are consistent with those in pre-Northridge frames. As reported by Gupta and Krawinkler ${ }^{[5]}$ based on extensive time history simulations, the main difference between the pre- 
and post-Northridge frames arise mainly in the local moment distribution in the beam and column connections. This is due to detailing factors such as the introduction of reduced beam sections or flange reinforcements. In fact, the time history simulations suggested that the global response and member force demands are virtually identical between preand post-Northridge frames designed for the same conditions. As a result, it is assumed that the splice demands used in this study (to follow) are fair representations of those in pre-Northridge frames.

Table 1 First four horizontal modal periods and fundamental vertical period for the 4-story and 20-story frames [s]

\begin{tabular}{cccccc}
\hline Frame story & $T_{1}$ & $T_{2}$ & $T_{3}$ & $T_{4}$ & $T_{V}$ \\
\hline 4-story & 0.94 & 0.28 & 0.15 & 0.09 & 0.09 \\
20-story & 2.37 & 0.84 & 0.48 & 0.34 & 0.30 \\
\hline
\end{tabular}

The splice locations in each considered frame are also indicated in Figure 2 using block arrows. In each spliced level, WCSs are located $1.2 \mathrm{~m}$ from the top surfaces of the lower story beams, which is the minimum distance requirement as per AISC 341-10 ${ }^{[40]}$ to reflect the least conservative scenario of the design standard. OpenSEES ${ }^{[42]}$ is used to develop highly detailed nonlinear models and simulate both frames.

In these two models, force-based fiber sections are created for all beams and columns, with the purpose to simulate axial force-moment interaction and to spread plasticity through the whole length of each structural member. The fiber sections also provide a direct examination of the tensile stress at various locations within the cross section. Reduced beam sections are also modelled as fiber elements to control the location of plastic hinge formation and the panel zones are considered as rigid links by multiplying a factor of 10 to the stiffness and strength of initial material of the models ${ }^{[41]}$. Finite joint sizes are modelled through rigid offsets. A bilinear kinematic hardening relationship is utilized to model the cyclic response of steel in the fiber sections, with modulus of elasticity $E$ equal to $2.0 \times 10^{5} \mathrm{MPa}$, a hardening slope equal to $5 \%$ of the initial elastic modulus, and yield strength $F_{y}$ equals to $380 \mathrm{MPa}$. These values were calibrated to match an extensive empirical dataset of plastic hinge responses obtained by Lignos et al. ${ }^{[43]}$ and are consistent with the previous modellings by Shaw et al. ${ }^{[15]}$, Galasso et al. ${ }^{[8]}$ as well as Stillmaker et al. ${ }^{[4]}$.

The selected constitutive model does not represent effective softening or deterioration due to effects such as local or lateral-torsional buckling. Although representation of such softening is important for simulating global instabilities such as collapse, it is (as the results, discussed later, indicate) of relatively modest significance here. In fact, fracture risk of WCSs is dominated by low- to medium- intensity ground shaking at which building deformations $(<\sim 3 \%$ MIDR) are not large enough to trigger these types of softening. This effect, noted previously by Galasso et al. ${ }^{[8]}$, is attributed to the saturation of stresses in WCSs at relatively low levels of hazard, owing to yielding in other elements of the structure (e.g., beams). Geometric nonlinearities, at both member- (i.e., $P-\delta$ ) and story- (i.e., $P-\Delta$ ) levels, are explicitly simulated using geometric transformations. A leaning column is also added in each model to capture the destabilizing effects of vertical forces on the gravity frames.

It is worth noting that fracture propagation is not simulated in this study, whose primary focus is to characterize WCS stress demands from the perspective of informing the need for retrofit at a component level, considering the failure of the first splice as the critical event controlling retrofit decisions. Nonetheless, propagation of fracture and its effect on building response is critical for a more holistic development of retrofit strategies. This has been addressed by the authors in Stillmaker et al. ${ }^{[4]}$, which required development of a special material in OpenSees to represent flange fracture.

\subsection{Selection of Ground-Motion Sets}

Different sets of unscaled earthquake records are properly selected. The adopted selection procedures are described and discussed in this sub-section.

\subsubsection{Ground-motion sets for selecting optimal IMs}

Unscaled ground-motion records selected from the SIMBAD (Selected Input Motions for displacement-Based Assessment and Design) database ${ }^{[45]}$ are used to perform cloud-based NLTHA. The considered database consists of 467 three-component accelerograms, including two horizontal (X- and Y-) and one vertical (Z-) components, obtained from 130 worldwide seismic events (covering mainshocks and aftershocks) included in various strong ground-motion databases assembled for different high-seismic regions. Specifically, all the records in SIMBAD come from shallow crustal earthquakes with moment magnitude $\left(M_{w}\right)$ ranging from 5 to 7.3 and epicentral distance ( $\left.R_{\text {epi }}\right)$ less than 35 
$\mathrm{km}$; a wide range of local site condition is also represented in SIMBAD. This results in a ground-motion database capable of providing strong ground motions of relevance for most of the design/assessment conditions of interest, avoiding the need for large scaling. From the full SIMBAD database, a subset of 100 ground-motion records is considered to provide a statistically significant number of strong-motion records of engineering relevance for the applications in this study. These records are arbitrarily selected for each building characterized by its $T_{1}$ (given in Table 1) by first ranking the 467 records in terms of their $S_{a}\left(T_{1}\right)$ values (by using the geometric mean of the two horizontal components) and then keeping the component with the larger $S_{a}\left(T_{1}\right)$ value (for the 100 stations with highest mean $S_{a}\left(T_{1}\right)$ ). It is worth noting that different ground motions are selected for the 4- and 20-story steel frames due to the different $T_{1}$ values for each frame. Also, site-specific record selection is outside the scope of this study. In fact, this choice is compatible with the cloud approach used here and the use of generic archetype structures.

Figures $3 \mathrm{a}$ and $3 \mathrm{c}$ show the 5\%-damped pseudo-acceleration response spectra of the selected 100 ground-motion records for 4- and 20-story case-study frames, respectively. The vertical dashed lines in these two figures indicate the fundamental horizontal periods of $4-\left(T_{1}=0.94 \mathrm{~s}\right)$ and 20 -story $\left(T_{1}=2.37 \mathrm{~s}\right)$ frames.
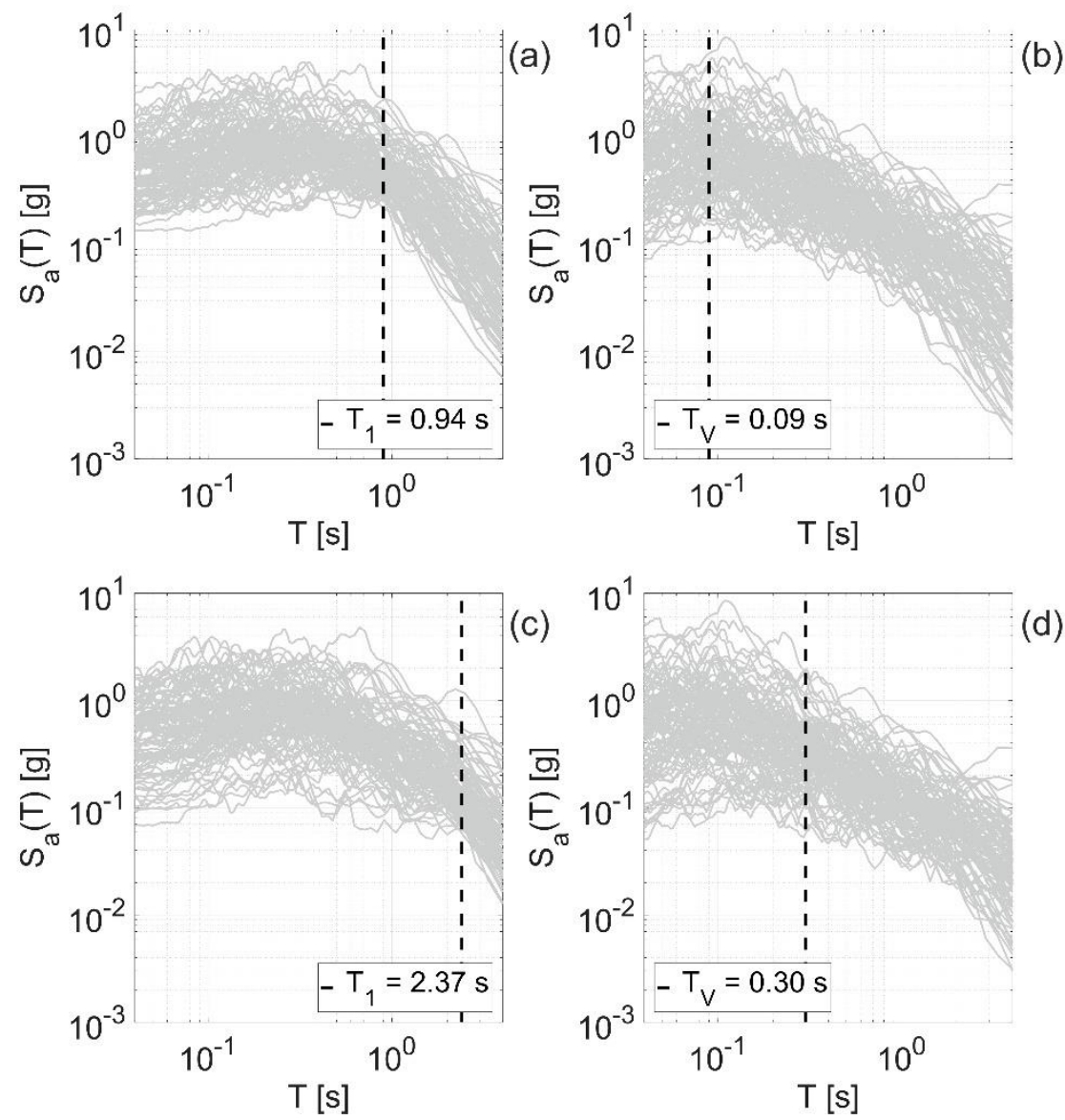

Figure 3 5\%-damped pseudo-acceleration response spectra for the 100 selected ground motions for Scenario 1 and 4-story frame (top panel), corresponding to (a) horizontal components, and (b) vertical components; and 20story frame (bottom panel), corresponding to (c) horizontal components, and (d) vertical components (vertical dashed lines represent the fundamental horizontal and vertical periods for the considered case-study frames)

3.2.2. Ground-motion sets for evaluating the effect of vertical ground-motion components on WCS stress demands The ground-motion records used for investigating the effect of the ground-motion vertical component on the seismic demand estimates of WCSs are obtained from the same database described above (i.e., SIMBAD). To investigate the 
effect of the vertical ground-motion component on the WCS stress demands $\left(\sigma_{D}\right)$ and quantify its increase induced by the vertical ground shaking, two strategies are employed:

(1) Selection of 100 ground-motion records with 'maximum' horizontal components (X- or Y-, 'maximum' to indicate the same selection criteria explained in Section 3.2.1) and corresponding vertical components (Z-);

(2) Selection of 100 earthquake records with 'maximum' vertical components (Z-) and their corresponding stronger horizontal components (between $\mathrm{X}$ - and $\mathrm{Y}$-).

For the first scenario (Scenario 1), the two sets of 100 ground motions selected in Section 3.2.1 for the 4- and 20story case-study frames (i.e., Figures $3 \mathrm{a}$ and $3 \mathrm{c}$ ) are employed. Then, their associated Z- components are selected as vertical counterparts from the same 100 recording stations. Pseudo-acceleration response spectra of these selected vertical ground motions are shown in Figures $3 \mathrm{~b}$ and $3 \mathrm{~d}$, respectively; the fundamental vertical periods of 4$\left(T_{V}=0.09 \mathrm{~s}\right)$ and 20-story $\left(T_{V}=0.30 \mathrm{~s}\right)$ frames are displayed as vertical dashed lines in these two figures.
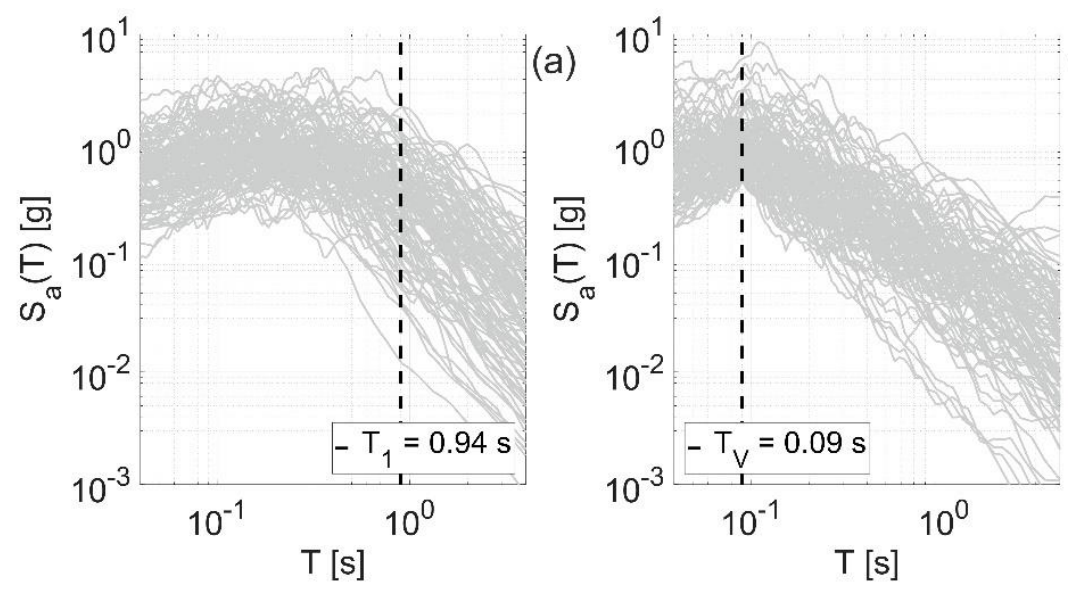

(b)
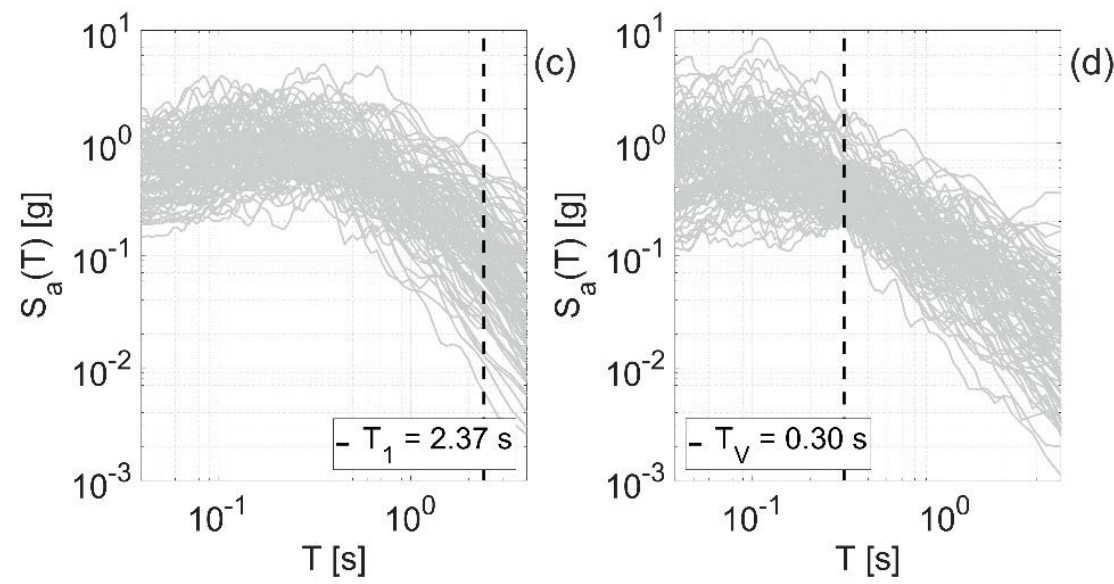

Figure 4 5\%-damped pseudo-acceleration response spectra for the 100 selected ground motions for Scenario 2 and 4-story frame (top panel), corresponding to (a) horizontal components, and (b) vertical components; and 20story frame (bottom panel), corresponding to (c) horizontal components, and (d) vertical components (vertical dashed lines represent the fundamental horizontal and vertical periods for the considered case-study frames)

For the second scenario (Scenario 2), a subset of 100 ground-motion records are selected for each considered frame characterized by its fundamental vertical period $\left(T_{V}\right)$ from SIMBAD. The values of spectral acceleration at $T_{V}$ for a damping ratio of $5 \%, S_{a}\left(T_{V}\right)$, for the 467 records (Z- components) are first calculated for 4- and 20-story frames: the 100 records characterized by the largest $S_{a}\left(T_{V}\right)$ values (for each building) are then selected to form the groundmotion sets. Figures $4 \mathrm{~b}$ and $4 \mathrm{~d}$ show the pseudo-acceleration response spectra (for a damping ratio of $5 \%$ ) of these 
selected vertical ground motions for 4- and 20-story frames, respectively. Following this, the stronger horizontal components (X-or Y-), i.e., those with the larger values of $S_{a}\left(T_{1}\right)$ corresponding to the same stations with the highest $S_{a}\left(T_{V}\right)$ values, are then employed (as presented in Figures 4a and 4c).

\subsection{Cloud Analysis}

The cloud analysis ${ }^{[38]}$ is a widely-used NLTHA procedure in which a structural model is subjected to a set of unscaled ground motions (each characterized by different IM values). This results in a "cloud" of EDP-IM pairs and the linear least squares is applied on those pairs to estimate the conditional mean and standard deviation of EDP given IM. In this study, cloud analysis of both 4- and 20-story frame models is carried out considering the ground-motion sets described above to obtain seismic demand estimates.

The simple power-law model in Eq. (5) is used in the cloud analysis:

$\mathrm{EDP}=a \mathrm{IM}^{b}$

This power-law model can be simply re-written as in Eq. (6), as a linear expression of the natural logarithm of the EDP and the natural logarithm of the $\mathrm{IM}^{[38]}$.

$\ln (\mathrm{EDP})=\ln (a)+b \ln (\mathrm{IM})+e$

In both equations above, $a$ and $b$ are the parameters of the regression; and $e$ in Eq. (6) is a zero-mean random variable representing the variability of $\ln (\mathrm{EDP})$ given the IM. The use of logarithmic transformation indicates that the EDPs are assumed to be conditionally lognormally distributed (conditional on the values of the IMs); this is a common assumption that has been confirmed as reasonable in many past studies.

The standard deviation of this linear regression-based probabilistic model $(s)$ is assumed to be constant with respect to IM over the range of IMs in the cloud and equal to:

$s=\sqrt{\frac{\sum_{i=1}^{N}\left[\ln \left(e d p_{i}\right)-\ln \left(a i m_{i}^{b}\right)\right]^{2}}{N-2}}$

In Eq. (7), $e d p_{i}$ and $N$ have same meaning of those in Eq. (4), and $i m_{i}$ is the IM value corresponding to the $i$-th ground motion. It is noteworthy to mention that significant heteroskedasticity may occur within some IM-EDP combinations and that this feature should be modelled explicitly when generating fragility functions, for example performing linear regressions locally in a region of IM values of interest (e.g., Freddi et al. ${ }^{[21]}$ ). However, the use of a less complex approach is chosen here as it adequately serves the purposes of this study.

\section{UNCERTAINTY CHARACTERIZATION OF FLANGE STRESS CAPACITY}

In this study, a fracture mechanics-based approach recently developed by Stillmaker et al ${ }^{[10]}$ is adopted to capture the uncertainty in stress capacity of WCSs (i.e., $\sigma_{C}$ ). This method primarily consists of four components: (1) advanced FEFM simulations based on the test data collected by Shaw et al. ${ }^{[15]}$; (2) functional forms development (to determine WCS stress capacity as a function of several parameters describing the splice geometry and material toughness property) based on the FEFM simulations; (3) uncertainties characterization for each input parameters, including modelling uncertainties; and (4) determination of WCS strength distribution through Monte Carlo simulation of these uncertainties.

The functional forms selected to estimate the WCS flange stress capacity are shown in Eqs. (8) - (13), including various parameters: (1) initial crack length, $a$; (2) top flange thickness, $t_{\text {upper }} ;$ (3) lower flange thickness, $t_{\text {lower }}$; (4) flange thickness ratio, $\zeta=t_{\text {upper }} / t_{\text {lower }} ;(5)$ crack penetration ratio, $\eta=a / t_{\text {lower }} ;$ and (6) Charpy V-Notch (CVN) value. 


$$
\sigma_{\text {capacity, estimate }}^{\text {flange }}=\frac{K_{I C}}{\sqrt{\pi \times(\eta / 2 \xi) \times t_{\text {upper }}}} \times \frac{1}{\xi \sqrt{\gamma} \times f_{1}(\eta) \times f_{2}(\xi) \times g_{1}(\eta) \times g_{2}(\xi)}
$$

The first term at the right side of Eq. (8) denotes a linear elastic fracture mechanics-based estimation of the allowable stress in an infinite plate with a center $\operatorname{crack}^{[46,47]}$. The critical stress intensity factor $K_{I C}$ could be determined from CVN by the expression in Eq. (9) ${ }^{[10]}$, which is the best fit rather than the lower-bound correlation derived by Barsom ${ }^{[48]}$ :

$$
K_{I C}=\sqrt{0.001 \times(0.979 \times C V N) \times E}
$$

The second term at the right side of Eq. (8) represents modifications to the stress capacity solution; the factor $\gamma$ in the denominator equals to 1 for center-cracked (CC) configuration of WCS while it equals to 2 for the edge-cracked (EC) case (refer to Stillmaker et al. ${ }^{[10]}$ for details). The rest four functions in the denominator could be expressed as:

$f_{1}(\eta)=A_{1} \eta^{2}+A_{2} \eta+A_{3}$

$f_{2}(\xi)=B_{1}(\xi-1)^{2}+B_{2}(\xi-1)+1$

$g_{1}(\eta)=\left(C_{1} K_{I C}^{3}+C_{2} K_{I C}^{2}+C_{3} K_{I C}\right) \eta+C_{4} K_{I C}^{3}+C_{5} K_{I C}^{2}+C_{6} K_{I C}+1$

$g_{2}(\xi)=\left(D_{1} K_{I C}^{2}+D_{2} K_{I C}+D_{3}\right)(\xi-1)^{2}+1$

The coefficients contained in Eqs. (10) - (13) (i.e., $A_{1}, A_{2}, \ldots, D_{2}, D_{3}$ ) have been calibrated by Stillmaker et al. ${ }^{[10]}$. Note that only two representative splices (i.e., labeled as Splice 1 and Splice 2 for the 4- and 20-story frames in Figure 2 , respectively) are selected, using a similar approach to that of Galasso et al. ${ }^{[8]}$. In this case, only one set of calibrated coefficients corresponding to both representative splices (out of four in total) is summarized in Table 2, which is edgecracked and unequal flange class (EC-UF). Table 2 also provides the mean value and standard deviation of the ratio $\sigma_{\text {capacity, FEM }}^{\text {flange }} / \sigma_{\text {capacity, estimate }}^{\text {flange }}$ by comparing the estimated stress capacity of Eq. (8) ( $\sigma_{\text {capacity, estimate }}^{\text {flange }}$ ) from stress capacity obtained via FEFM simulations ( $\left.\sigma_{\text {capacity, FEM }}^{\text {flane }}\right)$.

Table 2 Calibrated coefficients and fitting metrics for Eqs. (10) - (13) (adapted from Stillmaker et al. ${ }^{[10]}$ )

\begin{tabular}{lcc}
\hline Term & Coefficient & Splice 1 and Splice 2 (EC-UF type) \\
\hline$f_{1}(\eta)$ & $A_{1}$ & 4.31 \\
& $A_{2}$ & 0.247 \\
$f_{2}(\zeta)$ & $A_{3}$ & 1.12 \\
& $B_{1}$ & 4.25 \\
$g_{1}(\eta)$ & $B_{2}$ & 0.390 \\
& $C_{1}$ & $1.34 \times 10^{-6}$ \\
& $C_{2}$ & $-4.13 \times 10^{-4}$ \\
& $C_{3}$ & 0.0161 \\
& $C_{4}$ & $-6.91 \times 10^{-7}$ \\
& $C_{5}$ & $2.25 \times 10^{-4}$ \\
$g_{2}(\zeta)$ & $C_{6}$ & $-6.00 \times 10^{-3}$ \\
& $D_{1}$ & $2.48 \times 10^{-4}$ \\
& $D_{2}$ & -0.0697
\end{tabular}


According to Stillmaker et al. ${ }^{[10]}$, all the parameters in Eq. (8), including three geometric parameters (i.e., thickness of upper flange, $t_{\text {upper }}$; thickness of lower flange, $t_{\text {lower }}$; and crack length $a$ ) and a material parameter (i.e., CVN), are potential sources of uncertainty in the WCS fracture capacity model. Moreover, the estimation of $\sigma_{\text {capacity, estimate }}^{\text {flalso }}$

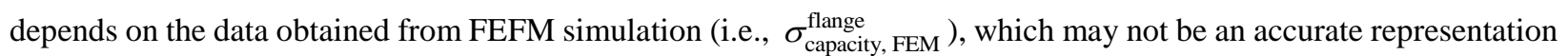
of the true flange stress capacity (assumed to be represented by the data from the experimental testing, $\sigma_{\text {capacity, test }}^{\text {flange }}$ ). To capture this modelling uncertainty arising from the capacity estimation equation, the true flange stress capacity $\sigma_{\text {capacity, true }}^{\text {flane }}$ can be decomposed as:

$\sigma_{\text {capacity, true }}^{\text {flang }}=\left(\frac{\sigma_{\text {capacity, test }}^{\text {flange }}}{\sigma_{\text {capacity, FEM }}^{\text {flange }}}\right) \times\left(\frac{\sigma_{\text {capacity, FEM }}^{\text {flange }}}{\sigma_{\text {capacity, estimate }}^{\text {flange }}}\right) \times \sigma_{\text {capacity, estimate }}^{\text {flange }}$

The first two terms in the decomposition above could be simulated as random variables (RVs). In summary, the uncertainty in $\sigma_{\text {capacity, true }}^{\text {flange }}$ may be due to the following three sources: (1) geometry; (2) material characteristics; and (3) modelling. All these sources of uncertainty are considered as RVs in the analysis and their statistical distributions, in terms of distribution type, bias factor (i.e., the ratio of the mean value of each RV to its nominal value) and coefficient of variation (CoV, i.e., the ratio between the standard deviation to the mean of each RV) are listed in Table 3. These statistics represent the input for Monte Carlo simulation. Further details on the uncertainty characterization for flange stress capacity estimation can be found in Stillmaker et al. ${ }^{[10]}$. Another source of uncertainty is that of the construction practice due to welding. Currently, there is a lack of data to simulate this effect in a meaningful way. Nonetheless, if such data becomes available, this type of variability may be easily incorporated into the analysis, for example, by further increasing the standard deviation in the fracture toughness, or the initial crack length.

Table 3 Statistical distribution of random variables in the uncertainty analysis (adapted from Stillmaker et

\begin{tabular}{lcccc} 
& & & & \\
\hline Category & Variable & Bias & CoV $(\%)$ & Distribution \\
\hline Geometry & Upper flange thickness $\left(t_{\text {upper }}\right)$ & 1.01 & 1.0 & Normal \\
& Lower flange thickness $\left(t_{\text {lower }}\right)$ & 1.01 & 1.0 & Normal \\
& Initial crack length $(a)$ & 1.01 & 3.0 & Normal \\
Material & Steel Charpy V-Notch toughness $(\mathrm{CVN})$ & 1.00 & 7.0 & Lognormal \\
Model & Error in correlation of Eq. (9) & 1.00 & 11 & Normal \\
& $\sigma_{\text {capacity, FEM }}^{\text {flange }} / \sigma_{\text {capacity, estimate }}^{\text {flange EC-UF-type WCS }}$ & 1.02 & 12.3 & Normal \\
& $\sigma_{\text {capacity, test }}^{\text {flange }} / \sigma_{\text {capacity, FEM }}^{\text {flange }}$ & 1.1475 & 6.5 & Normal \\
\hline
\end{tabular}

Additionally, the nominal values of upper flange and lower flange thicknesses are adopted from Shaw ${ }^{[41]}$ - for Splice 1, $t_{\text {upper }}$ is $48.01 \mathrm{~mm}$ (W14×257 section, $1.89 \mathrm{in}$ ) and $t_{\text {lower }}$ is $62.74 \mathrm{~mm}$ (W14×342 section, $2.47 \mathrm{in}$ ); while for Splice 2, $t_{\text {upper }}$ is $48.01 \mathrm{~mm}$ (W24×250 section, 1.89 in) and $t_{\text {lower }}$ is $57.91 \mathrm{~mm}$ (W24×306 section, $2.28 \mathrm{in}$ ). In general, a weld penetration of $50 \%$ of the smaller connected flange thickness was often specified in the seismic regions for pre-Northridge era ${ }^{[49]}$; as a result, the nominal initial crack length $(a)$ is assigned as half of $t_{\text {upper }}$. The typical value of CVN toughness is selected as $13.6 \mathrm{~J}$ for pre-Northridge $\mathrm{WCSs}^{[11]}$. 
According to the specified nominal/typical values and the defined statistical distributions of all the RVs, the uncertainties in the stress capacity of these two WCS flanges can be characterized through Monte Carlo simulation. As an example, Figure 5 shows the generated 1,000 random samples of the flange stress capacities ( $\left.\sigma_{C}\right)$ of Splice 1 (for the 4-story frame) and Splice 2 (for the 20-story frame), in the form of corresponding histograms fitted with lognormal distribution.
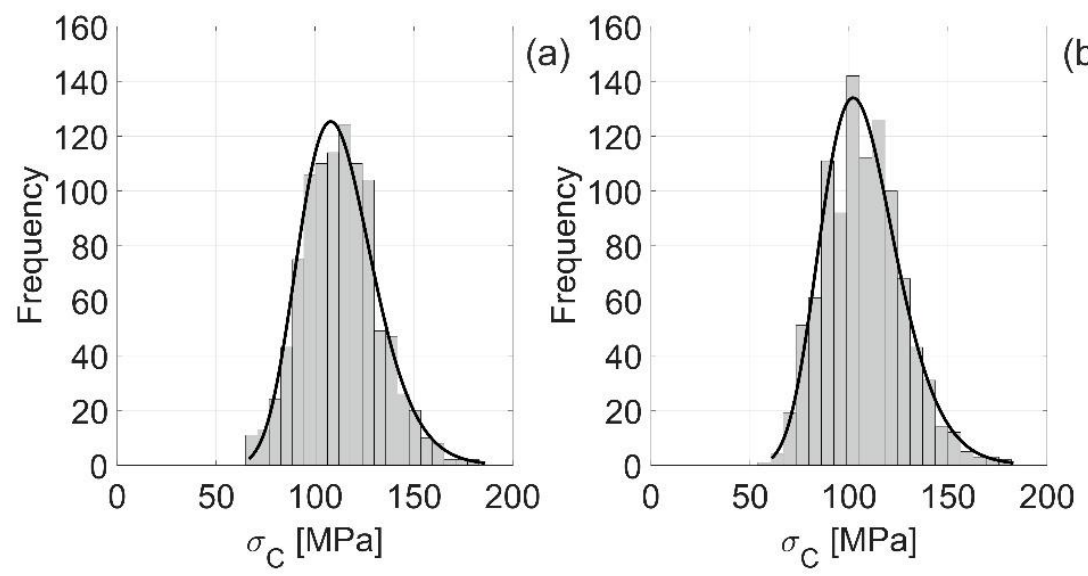

(b)

Figure 5 Examples of Monte Carlo simulation results in terms of flange stress capacities ( $\left.\sigma_{C}\right)$ of representative WCSs: (a) Splice 1 for the 4-story frame; (b) Splice 2 for the 20-story frame

A sensitivity analysis (not reported here for brevity) was performed to identify the number of samples required to estimate the distribution of the WCS fracture capacity through Monte Carlo simulation. In particular, the analysis was repeated by varying the number of samples for the Monte Carlo simulation from 100 to 10,000, with a step of 100 . Results of the analysis confirmed that 1,000 samples allow one to obtained 'stable' estimates of the WCS fracture capacity distributions and their parameters (and consequently, of fracture fragility) for the considered splices. Indeed, this result was expected given the assumed values of the CoVs for each random variable involved in Eqs. (8) - (14) (and Table 3).

\section{RESULTS AND DISCUSSION}

Results of the investigation on the seismic demand uncertainty of the 4- and 20-story case-study frames and for the two selected WCSs (i.e., Splice 1 and Splice 2) are presented in this section. Results for the other WCSs in the casestudy structures are not reported here for the sake of brevity. However, findings from the analysis are consistent across the full set of WCSs. In particular, according to Section 2, two main issues (i.e., optimal IM selection and inclusion of ground-motion vertical component) are investigated and discussed first. The fracture fragility assessment is performed for each considered issue, to quantify their effects on the fracture fragility parameters. Finally, the effect of the uncertainty characterizing fracture capacity $\left(\sigma_{C}\right)$ on the resulting fracture fragility is investigated using the proposed FEFM-based approach (described in Section 4).

\subsection{Optimal IM Selection}

In this sub-section, all the 41 considered IMs, including $S_{a}\left(T_{1}\right)$ (i.e., $I_{N p}$ with $\alpha=0$ ), $S_{a, a v g}\left(T_{i}\right)$ (i.e., $I_{N p}$ with $\alpha=1$ ) and $I_{N p}$ (with a range of $\alpha$-values between 0.1 and 0.9 ) with the four 'periods groups' (i.e., $\left(T_{i}\right)_{j}$, $j=1,2,3,4)$ defined in Section 2.1.1, are assessed based on the selection criteria introduced in Section 2.1. In particular, the overall performance of each considered IM, for each considered EDP (i.e., MIDR or $\sigma_{D}$, obtained through cloud analysis), is assessed by computing and comparing the quantitative parameters related to each tested criterion. Once the optimal IMs are determined for Splice 1 and Splice 2, results of the fragility analysis conditional to $S_{a}\left(T_{1}\right)$ (state-of-practice) and the optimal IM for each considered WCS are also compared and results are critically discussed. 


\subsubsection{Results of IM efficiency tests}

For sake of brevity, Figures $6 \mathrm{a}$ and $6 \mathrm{~b}$, and Figures $7 \mathrm{a}$ and $7 \mathrm{~b}$ only illustrate the scatter (cloud) plots of seismic demands in terms of MIDR and $\sigma_{D}$ versus $S_{a}\left(T_{1}\right)$ and the obtained optimal IMs, for each case-study frame and each selected WCS. The standard deviation ( $s$ ) of each logarithm regression is also given in the figures. To some extent, the visual inspection and the values of $s$ confirm that the IMs such as $I_{N p}$ and $S_{a, a v g}\left(T_{i}\right)$, which are able to account for the spectral shape in a range of periods of interest, are more efficient than $S_{a}\left(T_{1}\right)$.
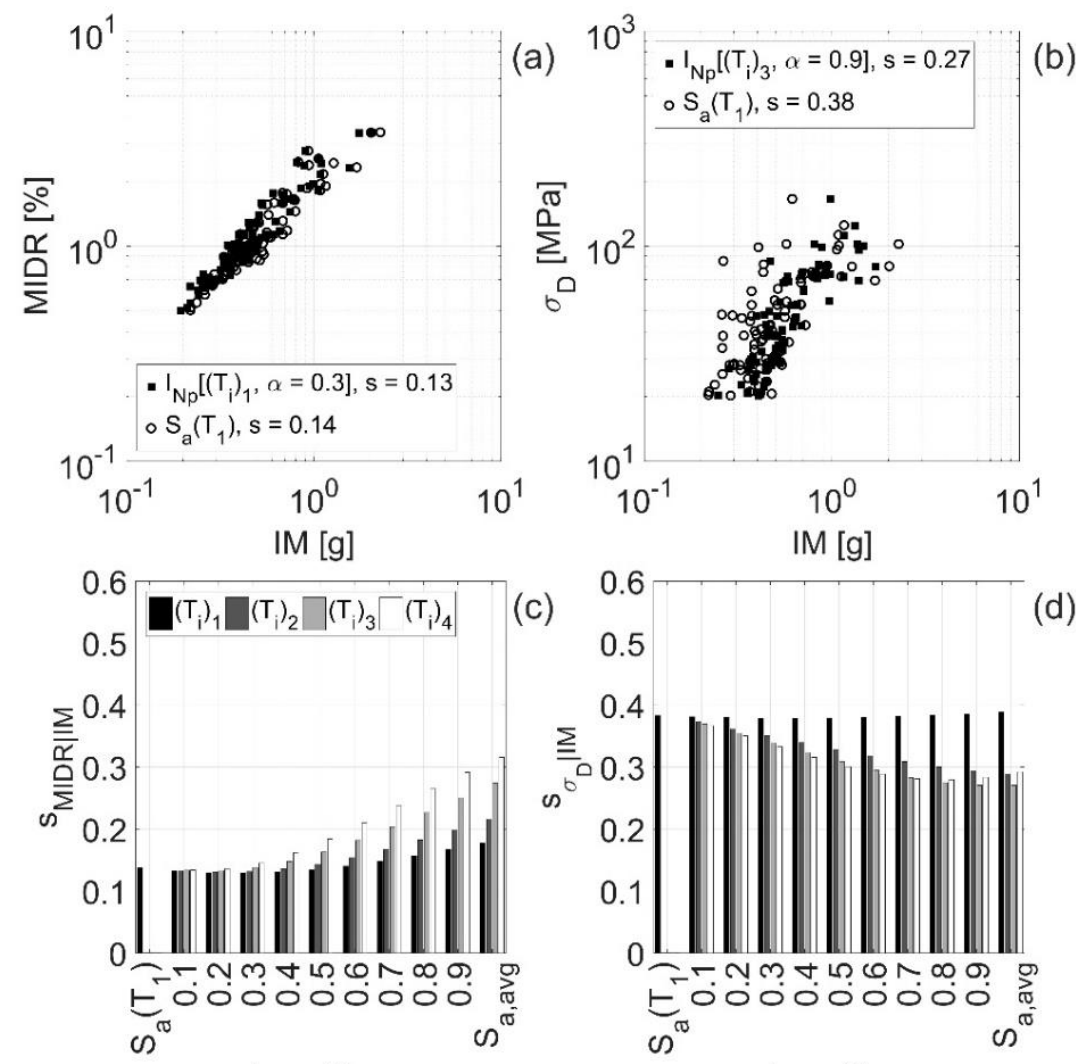

(d)
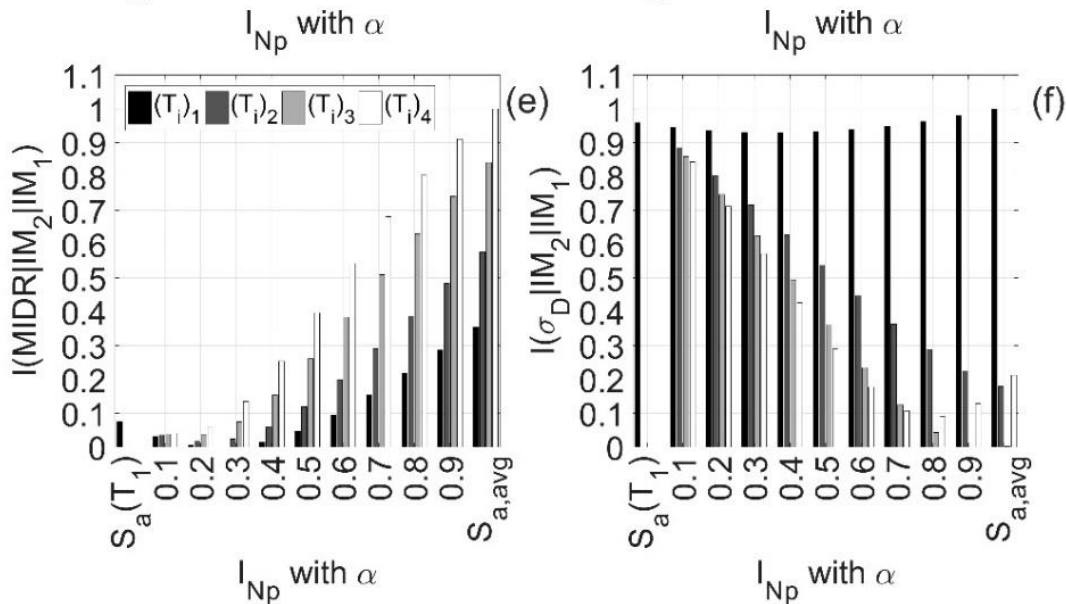

Figure 6 Results of optimal IM selection for the 4-story case-study frame: scatter plots of (a) MIDR, and (b) $\sigma_{D}$ versus optimal IM and $S_{a}\left(T_{1}\right)$; standard deviation (efficiency) of (c) MIDR, and (d) $\sigma_{D}$ for the considered IMs; and relative sufficiency measure for alternative IMs with respect to the IM characterized by the lowest standard deviation, for (e) MIDR, and (f) $\sigma_{D}$ 
To further expand on this, Figures $6 \mathrm{c}$ and $6 \mathrm{~d}$, and Figures $7 \mathrm{c}$ and $7 \mathrm{~d}$ display the standard deviation of residuals for MIDR and $\sigma_{D}$, for all the considered IMs and each case-study frame/splice. All these figures confirm that, when the $\alpha$-value of $I_{N p}$ approaches zero, $I_{N p}$ tends to approximate $S_{a}\left(T_{1}\right)$, resulting in almost identical values of $s$ between $\mathrm{EDP}-I_{N p}(\alpha=0.1)$ and EDP $-S_{a}\left(T_{1}\right)$, even if up to five periods of interest (i.e., $\left.\left(T_{i}\right)_{4}\right)$ are considered. Similarly, when the value of $\alpha$-parameter approaches one, $I_{N p}$ approximates the geometric mean of spectral acceleration values at considered periods, i.e., $S_{a, a v g}\left(T_{i}\right)$. Therefore, the $\alpha$-parameter used in the $I_{N p}$ definition is a proxy for the weight of the contributions of the spectral accelerations of higher modes and elongated period to each considered EDP. These four figures also show that accounting for higher-mode periods $\left(T_{2}, T_{3}\right.$ and $\left.T_{4}\right)$ and the elongated period $\left(1.5 T_{1}\right)$ has an impact on the efficiency of the considered IMs, but not always in a positive way. In most cases, especially when looking at Figures $6 \mathrm{~d}$ and $7 \mathrm{c}$, the use of more periods significantly reduces the standard deviation of EDP residuals, particularly in the case of $\sigma_{D}$ and the 20-story model. This is also observed in Figure $7 \mathrm{~d}$, where the most efficient IM in this case accounts for all five periods (i.e., $\left.\left(T_{i}\right)_{4}\right)$ considered in this study. However, a reverse effect is observed in Figure 6c (i.e., MIDR for the 4-story model), in which, considering more periods in $I_{N p}$ result in higher values of $s$ and this increase in $s$-values is more obvious with increasing $\alpha$-values in the $I_{N p}$ definition.

Based on the observations from the efficiency tests discussed above, general trends may be highlighted between considered IMs (i.e., both the state-of- practice IM, $S_{a}\left(T_{1}\right)$ and spectral shape-based IMs) and EDPs. For high-rise WSMRFs (e.g., 20-story frame model assessed in this study), higher dynamic modes (and elongated period) are important to properly capture structural response and seismic demand. This aspect, coupled with the force-controlled nature of WCS connections, result in high efficiency of the selected optimal IMs. In fact, seismic demands in these connections tend to saturate with increasing ground-motion intensity, as other elements in the structure (i.e. beams) yield, thereby limiting the force in the splices. As a result, adding up to four modes into $I_{N p}$ is beneficial for enhancing its efficiency, considering both EDPs. The $\alpha$-values of efficient IMs $\left(I_{N p}\right)$ for MIDR and $\sigma_{D}$ are 1.0 and 0.5 , respectively, this also indicates that the contribution of these higher modes (and elongated period in the case of MIDR) is crucial for both EDPs. In fact, if $\alpha$-value approaches one (and is greater than 0.5), it means that the effects of higher dynamic modes and elongated period (represented by $S_{a}\left(T_{i}\right)$ and $S_{a}\left(1.5 T_{1}\right)$, respectively) on $I_{N p}$ are equally important to $S_{a}\left(T_{1}\right)$. In the case of mid-rise WSMRFs (e.g., 4-story frame model assessed in this study), the prediction of MIDR is obviously not influenced by higher modes (or elongated period) and $S_{a}\left(T_{1}\right)$ may be considered as an efficient IM. However, the most efficient IM for $\sigma_{D}$ includes three dynamic modes and has an $\alpha$-value of 0.9 , which is quite consistent with the findings for the 20 -story frame model. Findings from this study may have general implications for other force-controlled elements as well.

In general, these findings are consistent with those of Kazantzi and Vamvatsikos ${ }^{[25]}$, Eads et al. ${ }^{[26,27]}$, and Kohrangi et al. ${ }^{[28]}$ amongst others, although all those studied just looked into global performance indicators (e.g., MIDR) rather than local ones (e.g., column splice demand) and collapse fragility.

\subsubsection{Results of IM relative sufficiency tests}

As discussed above, cloud analysis (Section 3.3) is used throughout the study, facilitating the computation of the relative sufficiency metric for the considered IMs. In fact, the PDF, $P[\mathrm{EDP}=e d p \mid \mathrm{IM}]$ in Eq. (4) can be calculated as follows, considering a lognormal distribution with the parameters (i.e., $a, b, s$ ) defined through the cloud analysis:

$$
P[\mathrm{EDP}=e d p \mid \mathrm{IM}]=\frac{1}{e d p \cdot s} \phi\left(\frac{\ln e d p-\ln \left(a_{i m^{b}}\right)}{s}\right)
$$

where $\phi(\cdot)$ is the standardized Gaussian PDF. Therefore, the relative sufficiency measure of Eq. (4) can finally be re-written as: 
$I\left(\mathrm{EDP}\left|\mathrm{IM}_{2}\right| \mathrm{IM}_{1}\right) \cong \frac{1}{N} \sum_{i=1}^{N} \log _{2} \frac{s_{1}}{s_{2}} \frac{\phi\left[\left(\ln e d p_{i}-\ln \left(a_{2} i m_{2}^{b_{2}}\right)\right) / s_{2}\right]}{\phi\left[\left(\ln e d p_{i}-\ln \left(a_{1} i m_{1}^{b_{1}}\right)\right) / s_{1}\right]}$

In Eq. (16), $a_{1}, b_{1}, s_{1}$ are the cloud parameters corresponding to $\mathrm{IM}_{1}$ while $a_{2}, b_{2}, s_{2}$ are the cloud parameters corresponding to $\mathrm{IM}_{2}$, and the other parameters are those of Eq. (4).
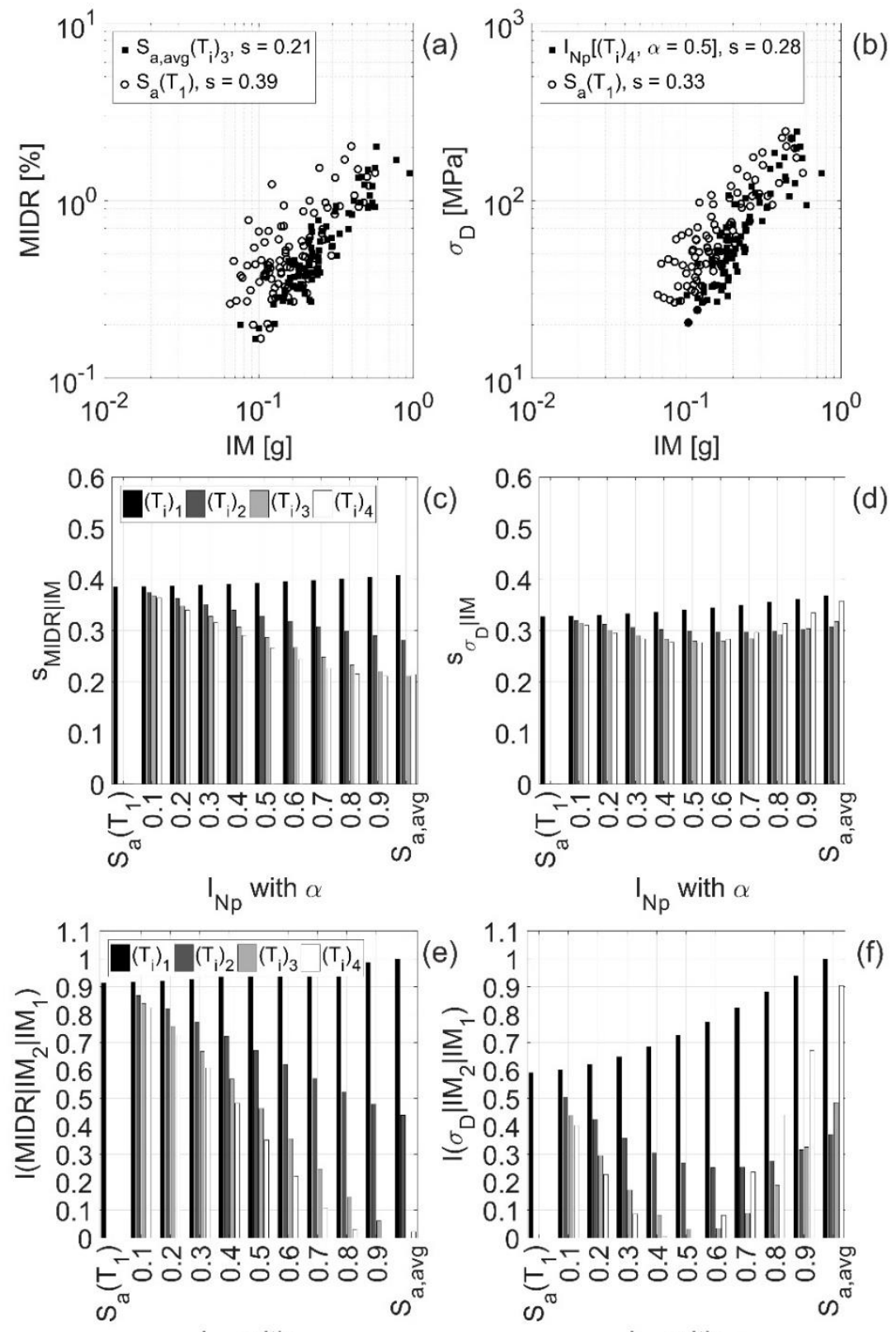

$\mathrm{I}_{\mathrm{Np}}$ with $\alpha \quad \mathrm{I}_{\mathrm{Np}}$ with $\alpha$

Figure 7 Results of optimal IM selection for the 20-story case-study frame: scatter plots of (a) MIDR, and (b)

$\sigma_{D}$ versus optimal IM and $S_{a}\left(T_{1}\right)$; standard deviation (efficiency) of (c) MIDR, and (d) $\sigma_{D}$ for the considered IMs; and relative sufficiency measure for alternative IMs with respect to the IM characterized by the lowest standard deviation, for (e) MIDR, and (f) $\sigma_{D}$ 
Figures $6 \mathrm{e}$ and $6 \mathrm{f}$, and Figures $7 \mathrm{e}$ and $7 \mathrm{f}$ present the absolute value of the relative sufficiency metric for all the 41 considered IMs (in terms of MIDR and $\sigma_{D}$ ) and both case-study frames - note that the actual sign of $I\left(E D P\left|\mathrm{IM}_{2}\right| \mathrm{IM}_{1}\right)$ is negative, i.e., any $\mathrm{IM}_{2}$ would provide less information compares to $\mathrm{IM}_{1}$; also, $I\left(E D P\left|\mathrm{IM}_{2}\right| \mathrm{IM}_{1}\right)$ values are normalized with respect to the maximum value for facilitating the plotting. In each figure, the reference $\mathrm{IM}_{1}$ is chosen as the one corresponding to the lowest $s$ value from the regression study (as also indicated in Figures $6 \mathrm{a}$ and $6 \mathrm{~b}$, and Figures $7 \mathrm{a}$ and $7 \mathrm{~b}$ ). According to all the figures, the $\mathrm{IM}_{1} \mathrm{~s}$ associated with the highest efficiency are also those characterized by the highest (relative) sufficiency.

\subsubsection{Discussion on hazard computability of selected optimal IMs}

As described in Section 2.1.4, the last criterion for the selection of optimal IMs is the hazard computability. For this criterion, the conventional IM employed in this study, $S_{a}\left(T_{1}\right)$, has obvious advantages over the other advanced IMs considered as numerous attenuation laws (or GMMs) and hazard maps have been developed for $S_{a}\left(T_{1}\right)$, for various period of engineering interest. In practice, the derivation of GMMs is still possible for $I_{N p}$ and $S_{a, a v g}\left(T_{i}\right)$ (i.e., the particular case of $I_{N p}$ with $\alpha=1$ ), through either direct or indirect methods. For instance, Bojórquez and Iervolino ${ }^{[29]}$ showed that GMMs for advanced, spectral-shape-based IMs can be easily derived through probabilistic combination of the available GMMs for $S_{a}\left(T_{i}\right)$ (i.e., indirect method) based on the assumption of jointly (log-) normality of spectral ordinates; on the other side, the direct method consists of deriving new specific GMMs for spectral-shapebased IMs. For instance, Kohrangi et al. ${ }^{[50]}$ recently developed empirical attenuation laws for $S_{a, a v g}\left(T_{i}\right)$, and the results of their study also indicate that the indirect method determines median estimates of $S_{a, a v g}\left(T_{i}\right)$ that are identical to those obtained from the direct method. It is worth noting that the variance estimates of $S_{a, \text { avg }}\left(T_{i}\right)$ from two methods may not be identical, if the attenuation law for $S_{a}\left(T_{1}\right)$ and the empirical correlation coefficients among different spectral acceleration ordinates are determined from different ground-motion record sets. To sum up, the advanced IMs accounting for the spectral shape effect are still computable, but this process (using either direct or indirect approach mentioned above) can be slightly more time-consuming, when compared with $S_{a}\left(T_{1}\right)$.

\subsubsection{Effects of optimal IMs on WCS fracture fragility}

Finally, two sets of fracture fragility functions, considering the selected optimal IMs and the mean fracture capacity ( $\sigma_{C}$, calculated based on the equations and deterministic/nominal values of RVs discussed in Section 4) are presented in Figure 8, for the 4- and 20-story frames, respectively. The corresponding sets of fracture fragility curves for the conventional, state-of-practice IM, $S_{a}\left(T_{1}\right)$, are also plotted for comparison. Table 4 lists the corresponding median $(\mu)$ and dispersion $(\beta)$ values for each fragility curve shown in Figure 8.
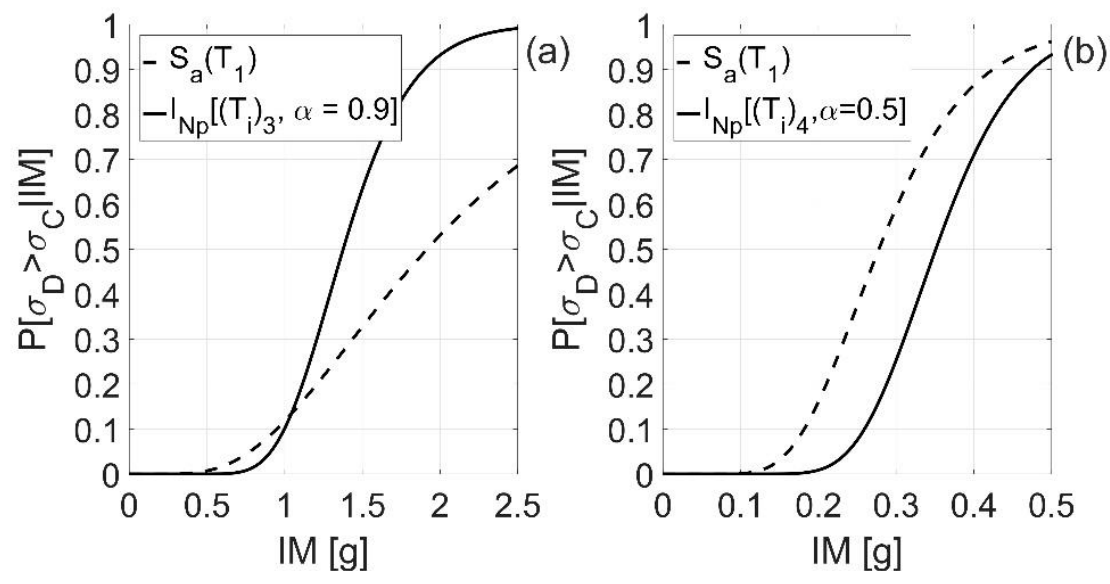
Figure 8 Comparison of fracture fragility curves derived based on the selected optimal IMs (solid lines) and $S_{a}\left(T_{1}\right)$ (dashed lines), for (a) Splice 1 (4-story frame); and (b) Splice 2 (20-story frame)

According to both Figure 8 and Table 4, the dispersions of fracture fragility functions for optimal IMs are considerably smaller than their counterparts for $S_{a}\left(T_{1}\right)$, as expected. It is obvious that the use of optimal spectralshape-based IMs reduces the variability in the fracture fragility analysis, and therefore, can better capture the actual fracture fragility of WCS.

Table 4 Median $(\mu)[\mathrm{g}]$ and dispersion $(\beta)$ values of fracture fragility curves obtained based on the selected optimal IMs and $S_{a}\left(T_{1}\right)$ (according to Figure 8)

\begin{tabular}{ccccc}
\hline \multirow{2}{*}{ Selected IM } & \multicolumn{2}{c}{ Splice 1 (4-story frame) } & \multicolumn{2}{c}{ Splice 2 (20-story frame) } \\
\cline { 2 - 5 } & $\mu$ & $\beta$ & $\mu$ & $\beta$ \\
\hline Optimal IM* & 1.38 & 0.25 & 0.35 & 0.24 \\
$S_{a}\left(T_{1}\right)$ & 1.92 & 0.55 & 0.28 & 0.33 \\
\hline
\end{tabular}

*Selected optimal IMs for Splice 1 and Splice 2 are $I_{N p}\left[\left(T_{i}\right)_{3}, \alpha=0.9\right]$ and $I_{N p}\left[\left(T_{i}\right)_{4}, \alpha=0.5\right]$, respectively.

\subsection{Effect of the Ground-Motion Vertical Component on WCS Fracture Fragility}

As described in Section 3.2.2, two sets of ground motions (i.e., Scenario 1 and Scenario 2, selected from SIMBAD), each containing the 100 stronger horizontal components (between X- and Y-) and their corresponding vertical components (Z-), are used as input to perform cloud-based NLTHA. To investigate the effect of the vertical groundmotion components on the fracture fragility of WCSs and quantify its potential increase, two sets of NLTHAs for each ground-motion scenario are run to assess the case-study frame models in terms of WCS stress demands $\left(\sigma_{D}\right)$, as follow:

(1) Application of the selected horizontal ground-motion components only;

(2) Application of both selected horizontal and vertical ground-motion components simultaneously.

Based on the two sets of runs, the fracture fragility curves (considering mean fracture capacity) developed for both case-study frames are shown in Figures 9 and 10, for Scenario 1 and Scenario 2 ground motions, respectively. The corresponding median $(\mu)$ and dispersion $(\beta)$ values for each fragility curve shown in these figures are summarized in Table 5. In order to reduce the sensitivity of the probability of fracture given IM, the optimal IMs selected in the previous sub-section (i.e., $I_{N p}\left[\left(T_{i}\right)_{3}, \alpha=0.9\right]$ for Splice 1 and $I_{N p}\left[\left(T_{i}\right)_{4}, \alpha=0.5\right]$ for Splice 2) are used here to derive fracture fragility curves for Scenario 1. Also, these two IMs are adopted to develop fracture fragility curves for Scenario 2. Following this, a fair comparison between the two scenarios can be performed.

In general, the increase of fracture fragility can be observed in all the four cases, when the vertical component of each ground motion is combined with its horizontal component. However, as confirmed by inspecting all the figures, the vertical component of each ground motion can be considered as a 'complementary' factor further increasing $\sigma_{D}$, but not the main contributor to $\sigma_{D}$. This increase in fracture fragility of WCSs is more significant in the case of the 20 -story frame compared to the 4-story frame, as expected. This reveals that the inclusion of ground-motion vertical components may be more critical in high-rise structures (increasing in $\mu$ up to about 20\%), as larger portion of seismic stress demands would be induced by vertical ground motions.

When comparing the results between the two scenarios, the higher fracture fragility of 4-story frame (representing mid-rise building) is observed in the case of Scenario 1. This is mainly due to the ground motion selection strategies described in Section 3.2.2 as Scenario 1 consists of all the strongest ground-motion horizontal components in the SIMBAD database, which always cause the higher seismic demand in WCSs compared to Scenario 2. However, the fracture fragilities of 20-story frame (representing high-rise building) between these two scenarios are almost identical (with slightly differences in dispersion). This indicates that high-rise frame is much more susceptible to fracture, and the fracture may occur even when it is subjected to ground motions with relatively lower intensities (i.e., Scenario 2). Moreover, the largest separation between the fracture fragility for the two sets of runs is observed in Figure 10b (i.e., 20 -story frame model subjected to Scenario 2 ground-motion set). This may be explained by the fact that the strongest 
ground-motion vertical components are selected for Scenario 2, and they may have comparable magnitudes to their horizontal components. Hence, a larger increase in $\sigma_{D}$ can be attributed to the vertical motions; this is in consistency with findings of previous researches (e.g., Papaleontiou and Roesset ${ }^{[33]}$ ).
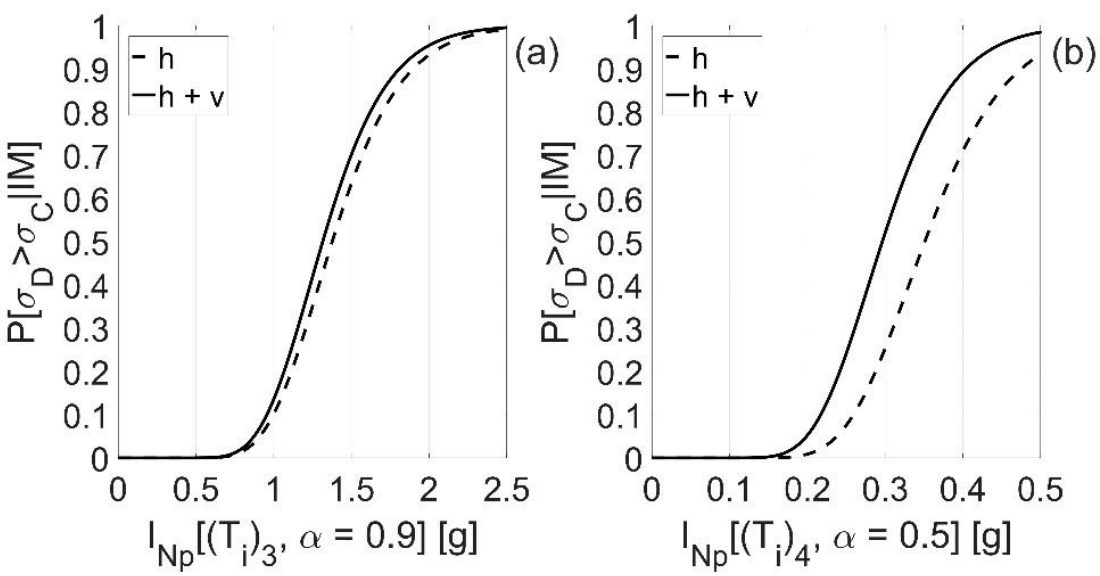

Figure 9 Comparison of fracture fragility curves derived in the case of horizontal components only (dashed lines) and horizonal components combined with vertical ones (solid lines) for Scenario 1 ground motions, and (a) Splice 1 (4-story frame); (b) Splice 2 (20-story frame)
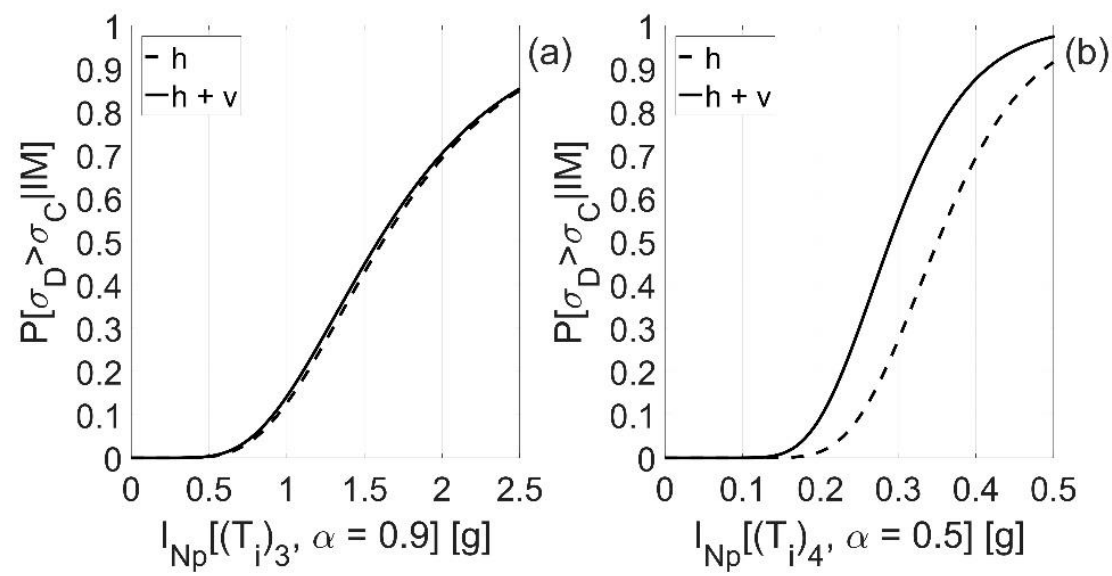

Figure 10 Comparison of fracture fragility curves derived in the case of horizontal components only (dashed lines) and horizonal components combined with vertical ones (solid lines) for Scenario 2 ground motions, and (a) Splice 1 (4-story frame); (b) Splice 2 (20-story frame)

Table 5 Median $(\mu)[\mathrm{g}]$ and dispersion $(\beta)$ values of fracture fragility curves obtained in the case of horizontal components only and horizonal components combined with vertical ones for Scenario 1 and Scenario 2 ground-motion sets (according to Figures 9 and 10)

\begin{tabular}{cccccc}
\hline & \multirow{2}{*}{ Cases } & \multicolumn{2}{c}{ Scenario 1 } & \multicolumn{2}{c}{ Scenario 2 } \\
\cline { 3 - 6 } & & $\mu$ & $\beta$ & $\mu$ & $\beta$ \\
\hline Splice 1 & horizontal & 1.38 & 0.25 & 1.62 & 0.42 \\
(4-story frame) & horizontal + vertical & 1.32 & 0.25 & 1.59 & 0.43 \\
Splice 2 & & & & \\
(20-story frame) & horizontal & 0.35 & 0.24 & 0.35 & 0.26 \\
\hline
\end{tabular}

Note: optimal IMs used for Splice 1 and Splice 2 (both scenarios) are $I_{N p}\left[\left(T_{i}\right)_{3}, \alpha=0.9\right]$ and $I_{N p}\left[\left(T_{i}\right)_{4}, \alpha=0.5\right]$, respectively. 


\subsection{Fracture fragility Analysis Accounting for Uncertainty in WCS Fracture Capacity}

To investigate the effect of fracture capacity uncertainty on WCS fracture fragility, the seismic stress demand distribution corresponding to the set of 100 strongest horizontal components of ground motions (described in Section 3.2.1) is considered. Following Section 4, the uncertainty of $\sigma_{C}$ (e.g., Figure 5) is assessed through Monte Carlo simulation, taking into account all the considered RVs (characterized by their nominal values and statistical distributions) specified in the FEFM-based approach proposed by Stillmaker et al. ${ }^{[10]}$.

Figure 11 shows the individual fracture fragility curves (with a range of median optimal-IM capacities, represented as grey lines) according to 1,000 realizations of the fracture capacity through Monte Carlo simulation, for the 4- (Splice 1) and the 20-story (Splice 2) case-study frames, respectively. The same figure also illustrates the mean, and the 5th and 95th percentile fracture fragility curves derived from the uncertainty simulation. In addition, a fracture fragility curve considering the mean of all the simulated $\sigma_{C}$ values is also plotted for comparison. As expected, the difference between mean fracture fragility curve derived from uncertainty analysis and the one accounting for the mean value of $\sigma_{C}$ are negligible. However, slightly higher dispersion (i.e., about $10 \%$ increase in $\beta$ ) is found in the mean fracture fragility curve (solid line), which provides a smeared representation ${ }^{[51]}$ of dispersion containing information on both the record-to-record variability (i.e., fracture stress demand) and the fracture capacity variability (e.g., in Figure 5, $\mathrm{CoV}$ of $\sigma_{C}$ is about $17 \%$ for both splices). On the other hand, the (smaller) dispersion of the fracture fragility curve corresponding to the mean value of $\sigma_{C}$ can only represent the uncertainty caused by the uncertainty of various ground-motion records used, since a discrete fracture capacity value (rather than an amount of equiprobable $\sigma_{C}$ data) is considered.

Moreover, both cases show significant scatter in the fracture fragility of WCSs when stress capacity uncertainty is considered. Giving this large variability of the fracture fragility, all the RVs considered in the employed FEFM-based approach should be carefully examined to identify their contribution to the total uncertainty in fracture capacity. Due to this significant uncertainty in the determination of $\sigma_{C}$, a more conservative value (rather than the mean value) of fracture capacity of WCS may be recommended, especially in the design practice. As an example, in the original paper of Stillmaker et al. ${ }^{[10]}$, a detailed reliability analysis has been conducted to calibrate the resistance factors added in design equations that can provide an adequate margin of safety for new construction of mid- to high-rise WSMRFs with WCSs.
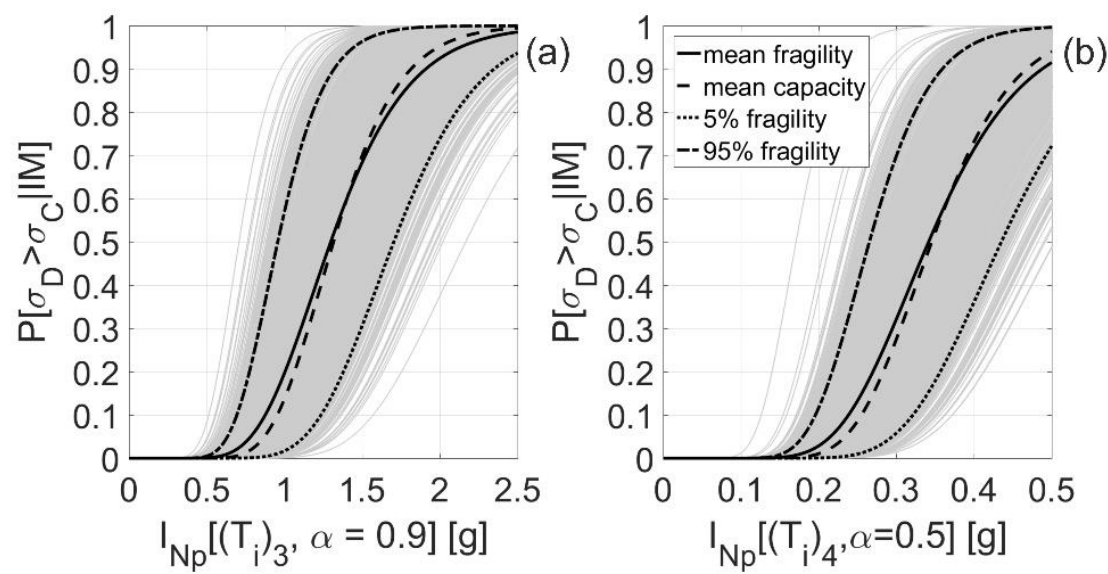

Figure 11 Fracture fragility curves considering uncertainty in fracture capacity of WCSs for (a) Splice 1 (4-story frame); and (b) Splice 2 (20-story frame)

\section{CONCLUSIONS}

This study investigated some issues affecting seismic demand and capacity uncertainties in the assessment of fracture fragility of WCSs. This led to refined (simulation-based) fracture fragility assessment for WCS connections, utilizing state-of-the-art research tools and putting them into a coherent and harmonized overall approach that is practical to implement.

On the basis of case-study 4- and 20-story WSMRF models and various sets of ground motions, several conclusions can be drawn as follow: 
(1) The spectral shape-based scalar IMs (i.e., $I_{N p}$ and its special case, $S_{a, a v g}\left(T_{i}\right)$, investigated in this study) are generally recognized as better proxies for probabilistic seismic demand analysis in terms of MIDR and $\sigma_{D}$, because they are usually characterized by higher efficiency and relative sufficiency, compared with $S_{a}\left(T_{1}\right)$. In terms of hazard computability criterion, these advanced IMs are computable although the process can be more time-consuming. Moreover, the performance of $I_{N p}$ is sensitive to the values of $\alpha$-parameter, and the effect of higher structural modes and elongated period. In the context of WCS connections, accounting for higher-mode effects on WCS seismic demands, through ad-hoc IMs, is particularly useful, since the stresses in these components saturate (at low intensity levels) as the ductile elements (beams in the case of moment frames) deform inelastically. According to this study, optimal $\alpha$-values and number of structural modes are usually structure-specific, although general trends can be observed depending on the type of EDP investigated;

(2) Accounting for the vertical components simultaneously with the corresponding horizontal components of ground motions increases the fracture fragility of WCSs, through an increase of the peak tensile stress in WCSs $\left(\sigma_{D}\right)$. This increase is moderate in the 4-story case-study frame and more considerable in the 20-story case-study frame. If the amplitudes of the ground-motion vertical components are comparable to their horizontal components, a significant increase in fracture fragility can be observed, and vice versa.

(3) Through the use of an advanced FEFM-based approach ${ }^{[10]}$ combined with a detailed uncertainty characterization, the variability in WCS fracture capacity is first assessed; the corresponding fracture fragility is then derived for the selected case-study frames/splices. Fracture fragility is significantly affected by the resulting capacity uncertainty, showing a considerable scatter around the mean fracture fragility. This suggests that a more conservative value (rather than the mean value) of fracture capacity of WCS may be considered in practical fracture risk assessment applications.

Findings from this study can guide similar performance-based assessment exercises for WSMRFs to inform, for instance, the planning and design of retrofitting strategies for WCSs and other vulnerable connections.

\section{ACKNOWLEDGEMENT}

The first author would like to acknowledge the financial support from China Scholarship Council (CSC) and University College London (UCL) through a joint research scholarship.

\section{REFERENCES}

1. Alali A, Anderson J, Beck. J, Benuska K, Bonowitz D, DiJulio R, et al. Analytical and Field Investigations of Buildings Affected by the Northridge Earthquake of January 17, 1994. Technical Report SAC 95-04. Sacramento, CA: SAC Joint Venture; 1995.

2. Alali A, Anderson J, Beck. J, Benuska K, Bonowitz D, DiJulio R, et al. Analytical and Field Investigations of Anderson JC, Gourley BC, Green M, Hajjar JF, Johnston R, Leon RT, et al. Technical Report: Case Studies of Steel Moment Frame Building Performance in the Northridge Earthquake of January 17, 1994. Technical Report SAC 95-07. Sacramento, CA: SAC Joint Venture; 1995.

3. Kaufman EJ, Fisher JW. A Study of the Effects of Material and Welding Factors on Moment Frame Weld Joint Performance Using Small-Scale Tension Specimen. Technical Report SAC 95-08. Sacramento, CA: SAC Joint Venture; 1995.

4. Maison BF, Kasai K, Dexter R, Ingraffea AR, Deierlein. GG. Selected Results from the SAC Phase I Beam-Column Connection Pre-Test Analyses. Report No. SAC/BD-96/01. Sacramento, CA: SAC Joint Venture; 1996.

5. Gupta A, Krawinkler H. Seismic Demands for Performance Evaluation of Steel Moment Resisting Frame Structures. Technical Report No. 132 (SAC Task 5.4.3). Stanford, CA: John A. Blume Earthquake Engineering Center, Stanford University; 1999.

6. American Institute of Steel Construction (AISC). Seismic Provisions for Structural Steel Buildings (AISC 341-16). Chicago, IL: American Institute of Steel Construction; 2016.

7. SAC Joint Venture. A Policy Guide to Steel Moment Frame Construction. FEMA 354. Washington, D.C.: Federal Emergency Management Agency (FEMA); 2000.

8. Galasso C, Stillmaker K, Eltit C, Kanvinde A. Probabilistic demand and fragility assessment of welded column splices in steel moment frames. Earthquake Engineering \& Structural Dynamics 2015; 44(11): 1823-1840. DOI: 10.1002/eqe.2557.

9. Nudel A, Marusich S, Dana M, Roufegarinejad A. Evaluation and Remediation of Pre-Northridge Steel Moment Frame Column Splices. Second ATC \& SEI Conference on Improving the Seismic Performance of Existing Buildings and 
Other Structures 2015, Reston, VA: American Society of Civil Engineers; 2015. DOI: 10.1061/9780784479728.024.

10. Stillmaker K, Kanvinde A, Galasso C. Fracture Mechanics-Based Design of Column Splices with Partial Joint Penetration Welds. Journal of Structural Engineering 2016; 142(2): 04015115. DOI: 10.1061/(ASCE)ST.1943541X.0001380.

11. Chi WM, Deierlein GG, Ingraffea A. Fracture Toughness Demands in Welded Beam-Column Moment Connections. Journal of Structural Engineering 2000; 126(1): 88-97. DOI: 10.1061/(ASCE)0733-9445(2000)126:1(88).

12. Bruneau M, Mahin SA. Full-Scale Tests of Butt-Welded Splices in Heavy-Rolled Steel Sections Subjected to Primary Tensile Stresses. Engineering Journal 1991; 28(1): 1-17.

13. Nuttayasakul N. Finite Element Fracture Mechanics Study of Partial Penetration Welded Splices. PhD Thesis. Stanford University, 2000.

14. Shen J, Sabol TA, Akbas B, Sutchiewcharn N. Seismic Demand on Column Splices in Steel Moment Frames. Engineering Journal 2010; 47(4): 223-240.

15. Shaw SM, Stillmaker K, Kanvinde AM. Seismic response of partial-joint-penetration welded column splices in moment-resisting frames. Engineering Journal 2015; 52(2): 87-108.

16. American Society of Civil Engineers (ASCE). Minimum Design Loads for Buildings and Other Structures (ASCE/SEI 7-16). Reston, VA: American Society of Civil Engineers; 2016.

17. Bradley BA. A critical examination of seismic response uncertainty analysis in earthquake engineering. Earthquake Engineering \& Structural Dynamics 2013; 42(11): 1717-1729. DOI: 10.1002/eqe.2331.

18. Papazoglou AJ, Elnashai AS. Analytical and field evidence of the damaging effect of vertical earthquake ground motion. Earthquake Engineering \& Structural Dynamics 1996; 25(10): 1109-1137. DOI: 10.1002/(SICI)10969845(199610)25:10<1109::AID-EQE604>3.0.CO;2-0.

19. Bozorgnia Y, Mahin SA, Brady AG. Vertical Response of Twelve Structures Recorded during the Northridge Earthquake. Earthquake Spectra 1998; 14(3): 411-432. DOI: 10.1193/1.1586008.

20. Di Sarno L, Elnashai AS, Manfredi G. Assessment of RC columns subjected to horizontal and vertical ground motions recorded during the 2009 L'Aquila (Italy) earthquake. Engineering Structures 2011; 33(5): 1514-1535. DOI: 10.1016/j.engstruct.2011.01.023.

21. Freddi F, Padgett JE, Dall'Asta A. Probabilistic seismic demand modeling of local level response parameters of an RC frame. Bulletin of Earthquake Engineering 2017; 15(1): 1-23. DOI: 10.1007/s10518-016-9948-x.

22. Baker JW, Cornell CA. A vector-valued ground motion intensity measure consisting of spectral acceleration and epsilon. Earthquake Engineering \& Structural Dynamics 2005; 34(10): 1193-1217. DOI: 10.1002/eqe.474.

23. Luco N, Cornell CA. Structure-Specific Scalar Intensity Measures for Near-Source and Ordinary Earthquake Ground Motions. Earthquake Spectra 2007; 23(2): 357-392. DOI: 10.1193/1.2723158.

24. Padgett JE, Nielson BG, DesRoches R. Selection of optimal intensity measures in probabilistic seismic demand models of highway bridge portfolios. Earthquake Engineering \& Structural Dynamics 2008; 37(5): 711-725. DOI: 10.1002/eqe.782.

25. Kazantzi AK, Vamvatsikos D. Intensity measure selection for vulnerability studies of building classes. Earthquake Engineering \& Structural Dynamics 2015; 44(15): 2677-2694. DOI: 10.1002/eqe.2603.

26. Eads L, Miranda E, Lignos DG. Average spectral acceleration as an intensity measure for collapse risk assessment. Earthquake Engineering \& Structural Dynamics 2015; 44(12): 2057-2073. DOI: 10.1002/eqe.2575.

27. Eads L, Miranda E, Lignos D. Spectral shape metrics and structural collapse potential. Earthquake Engineering \& Structural Dynamics 2016; 45(10): 1643-1659. DOI: 10.1002/eqe.2739.

28. Kohrangi M, Bazzurro P, Vamvatsikos D. Vector and Scalar IMs in Structural Response Estimation, Part II: Building Demand Assessment. Earthquake Spectra 2016; 32(3): 1525-1543. DOI: 10.1193/053115EQS081M.

29. Bojórquez E, Iervolino I. Spectral shape proxies and nonlinear structural response. Soil Dynamics and Earthquake Engineering 2011; 31(7): 996-1008. DOI: 10.1016/j.soildyn.2011.03.006.

30. Baker JW, Cornell CA. Spectral shape, epsilon and record selection. Earthquake Engineering \& Structural Dynamics 2006; 35(9): 1077-1095. DOI: 10.1002/eqe.571.

31. Minas S, Galasso C. Accounting for spectral shape in simplified fragility analysis of case-study reinforced concrete frames. Soil Dynamics and Earthquake Engineering 2019; 119: 91-103. DOI: 10.1016/j.soildyn.2018.12.025.

32. Jalayer F, Beck JL, Zareian F. Analyzing the Sufficiency of Alternative Scalar and Vector Intensity Measures of Ground Shaking Based on Information Theory. Journal of Engineering Mechanics 2012; 138(3): 307-316. DOI: 10.1061/(ASCE)EM.1943-7889.0000327.

33. Papaleontiou C, Roesset JM. Effect of vertical accelerations on seismic response of frames. In: Moan T, editor. Proceedings of the Second European Conference on Structural Dynamics: EURODYN '93, Trondheim, Norway, 21 23 June 1993, Rotterdam: Balkema; 1993.

34. Salazar AR, Haldar A. Structural responses considering the vertical component of earthquakes. Computers \& Structures 2000; 74(2): 131-145. DOI: 10.1016/S0045-7949(99)00031-0.

35. Macrae GA, Fields D, Mattheis J. Ground motion characteristic effects on multistorey steel frame response. Proceedings of the 12th World Conference on Earthquake Engineering, Auckland: New Zealand Society for 
Earthquake Engineering; 2000.

36. Di Sarno L. Seismic response of steel columns in MRFs under multi-axial earthquake components. Proceedings of the 7th International Conference on Behaviour of Steel Structures in Seismic Area: STESSA 2012, London: CRC Press; 2012.

37. Jalayer F, Cornell CA. Alternative non-linear demand estimation methods for probability-based seismic assessments. Earthquake Engineering \& Structural Dynamics 2009; 38(8): 951-972. DOI: 10.1002/eqe.876.

38. Jalayer F. Direct Probabilistic Seismic Anaysis: Implementing Non-linear Dynamic Assessments. PhD Thesis. Stanford University, 2003.

39. American Society of Civil Engineers (ASCE). Minimum Design Loads for Buildings and Other Structures (ASCE/SEI 7-05). Reston, VA: American Society of Civil Engineers; 2005.

40. American Institute of Steel Construction (AISC). Seismic Provisions for Structural Steel Buildings (AISC 341-10). Chicago, IL: American Institute of Steel Construction; 2010.

41. Shaw SM. Seismic Performance of Partial Joint Penetration Welds in Special Moment Resisting Frames. PhD Thesis. University of California, Davis, 2013.

42. Mazzoni S, McKenna F, Scott MH, Fenves GL. Open System for Earthquake Engineering Simulation User CommandLanguage Manual. OpenSees version 2.0. Berkeley, CA: Pacific Earthquake Engineering Research Center, University of California, Berkeley; 2009.

43. Lignos DG, Krawinkler H, Whittaker AS. Prediction and validation of sidesway collapse of two scale models of a 4story steel moment frame. Earthquake Engineering \& Structural Dynamics 2011; 40(7): 807-825. DOI: 10.1002/eqe.1061.

44. Stillmaker K, Lao X, Galasso C, Kanvinde A. Column splice fracture effects on the seismic performance of steel moment frames. Journal of Constructional Steel Research 2017; 137(2017): 93-101. DOI: 10.1016/j.jcsr.2017.06.013.

45. Smerzini C, Galasso C, Iervolino I, Paolucci R. Ground Motion Record Selection Based on Broadband Spectral Compatibility. Earthquake Spectra 2014; 30(4): 1427-1448. DOI: 10.1193/052312EQS197M.

46. Anderson TL. Fracture Mechanics: Fundamentals and Applications. 3rd ed. Boca Raton, FL: CRC Press, Taylor \& Francis Group; 2005.

47. Saxena A. Nonlinear Fracture Mechanics for Engineers. 1st ed. Boca Raton, FL: CRC Press; 1998.

48. Barsom JM. Development of the AASHTO fracture-toughness requirements for bridge steels. Engineering Fracture Mechanics 1975; 7(3): 605-618. DOI: 10.1016/0013-7944(75)90060-0.

49. Bruneau M, Mahin SA. Ultimate Behavior of Heavy Steel Section Welded Splices and Design Implications. Journal of Structural Engineering 1990; 116(8): 2214-2235. DOI: 10.1061/(ASCE)0733-9445(1990)116:8(2214).

50. Kohrangi M, Kotha SR, Bazzurro P. Ground-motion models for average spectral acceleration in a period range: direct and indirect methods. Bulletin of Earthquake Engineering 2018; 16(1): 45-65. DOI: 10.1007/s10518-017-0216-5.

51. Bakalis K, Vamvatsikos D. Seismic Fragility Functions via Nonlinear Response History Analysis. Journal of Structural Engineering 2018; 144(10): 04018181. DOI: 10.1061/(ASCE)ST.1943-541X.0002141. 